\title{
Phenotyping: Using Machine Learning for Improved Pairwise Genotype Classification Based on Root Traits
}

\author{
Jiangsan Zhao', Gernot Bodner' and Boris Rewald ${ }^{\text {* }}$ \\ ${ }^{1}$ Department of Forest and Soil Sciences, University of Natural Resources and Life Sciences, Vienna, Austria, ${ }^{2}$ Division of \\ Agronomy, Department of Crop Sciences, University of Natural Resources and Life Sciences, Vienna, Austria
}

\section{OPEN ACCESS}

Edited by:

Maria Carlota Vaz Patto,

ITQB-Universidade Nova de Lisboa,

Portugal

Reviewed by:

Anjali lyer-Pascuzzi,

Purdue University, USA

Joao Mendes Mendes-Moreira,

University of Porto, Portugal

*Correspondence:

Boris Rewald

rewald@rootecology.de

Specialty section:

This article was submitted to Crop Science and Horticulture,

a section of the journal

Frontiers in Plant Science

Received: 25 July 2016 Accepted: 25 November 2016 Published: 06 December 2016

Citation:

Zhao J, Bodner G and Rewald B (2016) Phenotyping: Using Machine Learning for Improved Pairwise

Genotype Classification Based on Root Traits. Front. Plant Sci. 7:1864. doi: $10.3389 /$ fpls.2016.01864
Phenotyping local crop cultivars is becoming more and more important, as they are an important genetic source for breeding - especially in regard to inherent root system architectures. Machine learning algorithms are promising tools to assist in the analysis of complex data sets; novel approaches are need to apply them on root phenotyping data of mature plants. A greenhouse experiment was conducted in large, sand-filled columns to differentiate 16 European Pisum sativum cultivars based on 36 manually derived root traits. Through combining random forest and support vector machine models, machine learning algorithms were successfully used for unbiased identification of most distinguishing root traits and subsequent pairwise cultivar differentiation. Up to $86 \%$ of pea cultivar pairs could be distinguished based on top five important root traits (Timp5) - Timp5 differed widely between cultivar pairs. Selecting top important root traits (Timp) provided a significant improved classification compared to using all available traits or randomly selected trait sets. The most frequent Timp of mature pea cultivars was total surface area of lateral roots originating from tap root segments at 0-5 cm depth. The high classification rate implies that culturing did not lead to a major loss of variability in root system architecture in the studied pea cultivars. Our results illustrate the potential of machine learning approaches for unbiased (root) trait selection and cultivar classification based on rather small, complex phenotypic data sets derived from pot experiments. Powerful statistical approaches are essential to make use of the increasing amount of (root) phenotyping information, integrating the complex trait sets describing crop cultivars.

Keywords: breeding, cultivar classification, pea (Pisum sativum L.), random forest (RF), root phenotyping, root trait selection, support vector machine (SVM)

\section{INTRODUCTION}

A policy report of the European Union noted recently that protein crops, e.g., bean, lentil, lupine, pea, and soya, are currently grown on $1.8 \%$ of arable land in the EU only, compared with $4.7 \%$ in 1961, and about $8 \%$ in Australia and Canada, 14.5\% in North America, and 25.5\% in South America (Jiang et al., 2004; EU, 2013; FAOSTAT, 2014; Cernay et al., 2015). This is despite grain legumes representing a significant source of protein for food (Vaz Patto et al., 2014; Multari et al., 2015) 
and feed (Jezierny et al., 2010; Koivunen et al., 2014), and legume cultivation reducing the need for $\mathrm{N}$ fertilizer even for subsequent crops in the rotation (Preissel et al., 2015). Recent studies have identified a comparative lack of breeding investment in Europe to improve grain legume adaptation to local agro-climatic conditions and management techniques (Annicchiarico and Iannucci, 2008; Lizarazo et al., 2015). While distinct leguminous crops are used locally for food and feed, and local cultivars are kept in numerous collections in gene banks, research institutions, and also in farms/home gardens, this genetic pool cannot be used at its full potential for large-scale agriculture and breeding programs until important traits have been determined.

Plant phenotyping intends measuring complex traits related to growth, yield, and adaptation to stress at different macroscopically scales of plant organization (Fiorani and Schurr, 2013). Examples for measured parameters are leaf vein structure (Sack and Scoffoni, 2013; Caringella et al., 2015), photosynthetic efficiency (Gilbert et al., 2011; Gorbe and Calatayud, 2012; Grady et al., 2013), root morphology (Iyer-Pascuzzi et al., 2010; Bucksch et al., 2014), biomass (Stachowicz et al., 2013; Poorter et al., 2015), and yield quantity and quality (Iqbal and Lewandowski, 2014).

Especially the modification of root system architecture (RSA) could contribute to improvements of desirable agronomic traits such as yield, drought tolerance, and resistance to nutrient deficiencies; thus, RSA was described key to a second green revolution improving resource use efficiency of crops (Lynch, 2007). For example, an architectural trait enhancing topsoil foraging is a higher number of basal roots - contributing significantly to phosphorous acquisition (Lynch, 2011), while deep rooting can, e.g., sustain water acquisition during drought periods or improve uptake of percolating nitrate (Pinheiro et al., 2005). Recently, an increased focus was laid on improving highthroughput, image-based root phenotyping approaches (Berger et al., 2010; Hartmann et al., 2011; Mairhofer et al., 2012; Fiorani and Schurr, 2013; Li et al., 2014). See Kuijken et al. (2015) for a recent review on the latest developments in root phenotyping and an overview on environmental and genetic factors influencing root phenotypes.

Advanced machine learning (ML) approaches encompass promising statistical tools for variable selection and group classification. While the use of ML approaches in nongenetic/biochemical plant sciences is still scarce, ML was introduced to promote RSA classification in the recent past (Zhong et al., 2009; Iyer-Pascuzzi et al., 2010). Iyer-Pascuzzi et al. (2010) use of ML methods mainly benefited from using a noninvasive imaging system which enabled them to acquire 16 traits from a high number of pictures [ 200 (pseudo-)replicates per genotype]. However, the limited plant age and highly artificial growth conditions are major disadvantages of many non-invasive and high-throughput root phenotyping methods (Bucksch et al., 2014): RSA differs with ontogeny (Hargreaves et al., 2009; Wojciechowski et al., 2009; Hund et al., 2011) and is highly plastic to edaphic conditions (Tracy et al., 2012; Rich and Watt, 2013). Thus, analyses on mature plants in situ or under more realistic growth conditions, which mostly rely on manual, destructive methods [e.g., 'shovelomics'; Trachsel et al. (2011)] continue to be essential although the number of replicates and measurements is often limited but the complexity of variables (i.e., traits) remains high. Similar to the situation in cell biology (Sommer and Gerlich, 2013), available ML approaches in plant sciences have been optimized for large-scale screenings, probably partially due to the difficulty in applying ML algorithms with unbiased variable selection on low number of replicates (Bucksch et al., 2014).

Among supervised ML algorithms, random forest (RF) is a non-parametric method with high accuracy and robustness to noise (Breiman, 2001). RF has been applied in several biological fields, like gene (Díaz-Uriarte and De Andres, 2006) and protein sequence (Pan and Shen, 2009) selection, and disease prediction (Yang et al., 2014). However, most previous studies mainly focused on improving classification accuracy with variable selection rather than variable interpretation (Liu et al., 2014; da Costa et al., 2015; Gowin et al., 2015) because the variable importance measure is biased in the standard RF algorithm overestimating the importance of correlated predictor variables (Strobl and Zeileis, 2008). However, unbiased variable selection is essential to stable classification and meaningful interpretation of plant traits and other data and can be achieved by using an improved RF algorithm - based on a conditional permutation scheme as a computational means to determine variable importance (Strobl and Zeileis, 2008; Strobl et al., 2008). Support vector machines (SVMs) are another set of supervised ML methods which can be trained to classify individuals in high-dimension space (Cortes and Vapnik, 1995). SVMs have been widely used in neuro-image classification (Gaonkar and Davatzikos, 2013) and face detection (Shan, 2012). SVMs can be differentiated based on kernel functions (Okkan and Serbes, 2012): linear kernel functions (linear SVMs) were previously used for variable selection of root systems (Iyer-Pascuzzi et al., 2010). However, variable selection by ranking absolute values of weights are biased, as the absolute weight values of irrelevant variables can be as high as of important ones (Statnikov et al., 2006; Gaonkar and Davatzikos, 2013). SVMs based on Gaussian radial basis function (rbf) kernel often provide a better performance on 'noisy' data sets not separable linearly - resulting in the more widely use of rbf SVMs in classification (Hsu et al., 2010).

Powerful statistical approaches are essential to make use of the increasing amount of (root) phenotyping information, integrating the complex trait sets (describing RSA). Combining RF with rbf SVMs for variable selection and group classification, respectively, might overcome problems in applying ML approaches on data sets characterized by a rather low signalto-noise ratio such as manually derived phenotyping data (Liu et al., 2004). For example, Löw et al. (2012) found a significantly higher classification accuracy of pre-crops in two out of four agricultural regions using satellite images when applying a combination of RF and SVMs compared to using either RF or SVMs for both trait selection and classification. Thus, aims of this study were to determine if (i) RF can be reproducible used for selecting important root traits (i.e., root traits distinguishing mature pea cultivars), and (ii) how root trait selection influences cultivar classification by rbf SVMs. We hypothesize that rbf SVMs classification is superior to traditional univariate tests if important root traits are identified by RF. Pisum sativum L. was 
selected as test species because it is one of the most frequently cultivated grain legumes worldwide (Alves-Carvalho et al., 2015), with especially European genetic resources still insufficiently characterized.

\section{MATERIALS AND METHODS}

\section{Plant Material and Experimental Set-Up}

Sixteen randomly selected cultivars of pea ( $P$. sativum L.) were used for root phenotyping (Table 1), originating either from Southern (Portugal and Spain) or Northern Europe (Estonia, Latvia, Norway, and Sweden). Seeds were provided by partners within the EU FP7 project 'Eurolegume' and by the Nordic gene bank.

Experiments were conducted in a large plastic foil greenhouse from June 13th, 2014 to October 7th, 2014 located in Tulln, Austria $\left(48.33^{\circ} \mathrm{N}, 16.05^{\circ} \mathrm{E}\right)$. Aeration openings of the greenhouse were fitted with mesh to prevent insect infestations. Solar radiation, air temperature, and relative humidity were hourly recorded $2 \mathrm{~m}$ above ground; mean air temperature during the measurement period was $20.7^{\circ} \mathrm{C}$, relative humidity ranged between $18.6-87.7 \%$ with a mean of $59.9 \%$. Mean daily sum of solar radiation was $13.28 \mathrm{MJ} \mathrm{m}^{-2}$ day $^{-1}$, with a maximum of $27.41 \mathrm{MJ} \mathrm{m}^{-2}$ day $^{-1}$ at July 1 st; day length (solar radiation $\geq 120 \mathrm{~W} \mathrm{~m}^{-2}$ ) varied between 10 and $16 \mathrm{~h}$.

\begin{tabular}{|c|c|c|c|}
\hline Abbreviation & Cultivar & $\begin{array}{c}\text { Country of } \\
\text { origin }\end{array}$ & $\begin{array}{c}\text { Donor } \\
\text { institution }\end{array}$ \\
\hline ps1.Estonia & Eesti hall & Estonia & ECRI \\
\hline ps2.Estonia & $\begin{array}{l}\text { Eesti kollane } \\
\text { soogihernes }\end{array}$ & Estonia & ECRI \\
\hline ps3.Estonia & Jõgeva roheline & Estonia & ECRI \\
\hline ps4.Estonia & Seko & Estonia & ECRI \\
\hline ps5.Latvia & Alma & Latvia & SPPBI \\
\hline ps6.Latvia & Bruno & Latvia & SPPBI \\
\hline ps7.Latvia & $\begin{array}{c}\text { k-4833 Stendes } \\
\text { Hero }\end{array}$ & Latvia & SPPBI \\
\hline ps8.Latvia & Retrija & Latvia & SPPBI \\
\hline ps9.Norway & NGB 10778.1 & Norway & NordGen \\
\hline ps10.Norway & NGB 20045.3 & Norway & NordGen \\
\hline ps11.Portugal & Gp 3263 & Portugal & INIAV \\
\hline ps12.Portugal & Gp 3491 & Portugal & INIAV \\
\hline ps13.Portugal & Gp 3497 & Portugal & INIAV \\
\hline ps14.Portugal & Grisel & Portugal & INIAV \\
\hline ps15.Sweden & NGB 1025131 & Sweden & $\begin{array}{l}\text { NordGen/ } \\
\text { Uppsala U }\end{array}$ \\
\hline ps16.Sweden & NGB 131381 & Sweden & $\begin{array}{l}\text { NordGen/ } \\
\text { Uppsala U }\end{array}$ \\
\hline
\end{tabular}

ECRI, Estonia Crop Research Institute; NordGen, Nordic Genetic Resource Center, Norway; INIAV, Instituto Nacional de Investigação Agrária e Veterinária, Portugal; SPPBI, Priekuli Plant Breeding Institute, Latvia; Uppsala U, Uppsala University, Sweden.
Seeds of all cultivars were germinated in a growth chamber (Fitotron; Weiss-Gallenkamp, UK) at $25 \pm 1^{\circ} \mathrm{C}$. Seeds were coated with a rhizobium suspension (Steinberga et al., 2008) before being planted in 0.5 -L plastic bags $(10 \mathrm{~cm}$ high) filled with washed quartz sand (0.7-1.2 mm-sized) amended with $1 \mathrm{~g}$ of slow release fertilizer (Osmocote Pro 3-4M; 17-11-10+2MgO+TE; ICL Specialty Fertilizers, Tel Aviv, Israel). Initial germination was conducted in darkness; after the first seed germinated, light (PAR $350 \mu \mathrm{E} \mathrm{m} \mathrm{m}^{-2} \mathrm{~s}^{-1}$ ) was turned on (16 h light/8 h dark). Germination time varied between 4 and 6 days with minor differences between cultivars (data not shown). After 1014 days, eight similar-sized seedlings per cultivar were selected for transplanting.

In the greenhouse, eight blocks of 16 plastic tubes each (128 tubes in total) were established on wooden frames in North to South direction. The plastic tubes used as pots/growing cylinders in the experiments were $108 \mathrm{~cm}$ long and $20 \mathrm{~cm}$ in diameter ( $232 \mathrm{~L}$ ); the bottom was sealed with a cap; holes covered with a glass fiber mat allowed for free drainage. Before the tubes were filled with washed, 0.7-1.2 mm-sized quartz sand, a plastic liner was installed in each tube allowing for undisturbed removal of the substrate during harvest; the liner was perforated at the bottom $10 \mathrm{~cm}$. Measurements in large plastic tubes have previously shown good agreement with maximum rooting depth and root length density as determined in the field and have been used to explore root traits in other legumes such as chickpea (Kashiwagi et al., 2006; Vadez et al., 2008). For transplanting, germination bags were placed inside the tubes and cut open at the side and bottom to prevent root disturbance. One plant per cultivar was randomly arranged in each of the eight blocks. $8.3 \mathrm{~g}$ of an AMF inoculum (Glomus mosseae BEG95, G. intraradices, and G. geosporum BEG199; supplied by Dr. Aleš Látr, Symbiom, Czech Republic) were added to each plant individual around the root systems at depths of $0-10 \mathrm{~cm}$ before the tube was brimmed with additional sand. An automated, pressure-compensated dripirrigation system was used to supply all plants with ample amounts of water and a modified Long Ashton nutrient solution (Jia et al., 2004); amounts were adjusted to increasing plant size and weather conditions.

\section{Harvest and Analysis}

Plants were randomly harvested within blocks at 71-92 days after transplanting. After harvesting the shoots (data not shown), the tubes were placed horizontally and the plastic liner was pulled out on a $1.5 \mathrm{~mm}$-mesh table. After the plastic liner was cut open, roots were then manually excavated as previously described by Kashiwagi et al. (2005) and others. No roots reached the bottom of the tube and few roots were discovered at the sides, indicating a rather unrestricting pot size. After the root system was uncovered, the maximum rooting depth was determined. It was further washed and rinsed in a bucket filled with clean tap water (Miguel, 2012), photographed next to a size standard, stored in a water-filled plastic bag, and transported to the lab for further analysis. Detached (i.e., shed/broken off) root segments were accurately collected from the remaining sand on the mesh table (mesh size: $2 \times 2 \mathrm{~mm}$ ), stored in paper bags and transported to the lab, oven dried $\left(65^{\circ} \mathrm{C}, 48 \mathrm{~h}\right)$ and added to root biomass. In 
the lab, the root systems were stored at $4^{\circ} \mathrm{C}$ until further analysis ( $\leq 3$ weeks) took place (Hu et al., 2013).

For in-depth architectural and morphological analysis, the root systems of 5-7 plant individuals per cultivar (97 plants in total) were manually dissected into tap root and laterals. Laterals along the tap root and the tap root were separated into the five depth classes $0-5,5-10,10-20,20-40$, and $40-100 \mathrm{~cm}$. Three lateral root samples from the depth classes $0-5,5-10$, and $10-$ $20 \mathrm{~cm}$ along the tap root were scanned in water-filled trays (Epson Expression 10000XL; Epson, Nagano, Japan) at $400 \mathrm{dpi}$, grayscale. Pictures were analyzed for diameter, surface area, length, and volume with the PC program WinRhizo 2012b Pro (Régent Inst., Ville de Québec, QC, Canada). Subsequently, all root samples were dried $\left(65^{\circ} \mathrm{C}, 48 \mathrm{~h}\right)$ and weighed to an accuracy of $\pm 0.1 \mathrm{mg}$ (CP225D; Sartorius, Göttingen, Germany). The specific root area (SRA, $\mathrm{cm}^{2} \mathrm{~g}^{-1}$ ), specific root length ( $\mathrm{SRL}, \mathrm{cm} \mathrm{g}^{-1}$ ), tissue density (TD, $\mathrm{g} \mathrm{cm}^{-3}$ ), the total root surface area (totalRSA), root length (RL), and root volume were calculated. Determined root traits (Guo et al., 2008; Rewald et al., 2011) are listed in Table 2 (Cramer et al., 2007; Alves-Carvalho et al., 2015).

\section{Data Analysis}

Thirty-six root traits in total, either directly measured or calculated, were available for analysis (Table 2). Non-normal distributed root traits were box-cox transformed with 'MASS' package, version 7.3-44, in $\mathrm{R}$ for Windows version 3.2.2 ( $\mathrm{R}$ Core Team, 2015). Multiple imputation was conducted by 'Amelia' package, version 1.7.3. The $\mathrm{R}$ code used for data preparation can be found as Supplementary Method S1.

\section{Random Forest and Support Vector Machines}

Random forest (Breiman, 2001; Strobl et al., 2009) was used to rank root traits according to their importance for classification; SVMs (Vapnik and Vapnik, 1998) were used for multiclass or pairwise cultivar classification. A flow chart outlining data handling steps can be found as Supplementary Method S2.

Because the multiclass classification resulted in very low accuracy (see Supplementary Figure S1), only the pairwise classification was pursued further. In order to use the 'cforest' function in the R 'Party' package (version 1.0-23) for root traits importance measure, individuals of each pair of cultivars were oversampled four-times (to gain the number of data points required by the software algorithm) for pairwise classification. As RF was used for traits important measure only, the whole oversampled data set was used. Afterward, the number of root traits randomly chosen at each split (building each tree), $m$ try, was tuned. Even though it has been suggested that $m$ try $=\sqrt{n}$, $n$ is the amount of root traits, always generates acceptable classification accuracy (Díaz-Uriarte and De Andres, 2006), the accuracy might vary (Verikas et al., 2011). Thus, 1000 trees with 14 mtrys (i.e., using $1,2,4,6,8,10,12,14,16,18,20,24,28$, or 32 traits), were constructed in RF to determine the importance of each root trait in each pairwise comparison. In a third step, root traits were ranked in each pair based on their importance. Root traits importance was calculated in RF based on unbiased conditional inference permutation test (Strobl and Zeileis, 2008; Ball et al., 2014). The most important root trait was defined as the one leading to the highest mean decrease of classification accuracy when values of a variable are randomly permuted across all 1000 trees (Breiman, 2001). Because negative importance values are due to random variation around zero (Strobl et al., 2009), values of root traits importance were first subtracted by the absolute value of the lowest negative importance and then normalized between 0 and 1 before being ranked in each pair.

Cultivar classification by either SVMs or RF were conducted through passing different combinations of top ranking important root traits derived from RF to SVMs/RF classification models. In order to find the combination of top ranking important root traits (Timp) that generate SVMs/RF models with the highest overall prediction accuracy, different numbers of Timps (Timpi) were tested in SVMs/RF classification. Even though the number of variables in final SVMs models should generally be $<10$ (Nicodemus et al., 2010), nine trait combinations were tested: top $i$ important root traits (Timpi $=2,3,5,7,9,11,13,15$ ) and all root traits (36). In rbf SVMs models, twelve kernel parameter $C$ and regularization parameter gamma (Meyer, 2015) from $10^{-5}$ to $10^{6}$ were tuned; the best combination of $C$ and gamma leading to the highest prediction accuracy was chosen through leave-one-out cross-validation (LOOCV; Kohavi, 1995). Each SVMs pairwise classification model was validated with LOOCV. The accuracies of RF classification were derived from out of bag error (OOB); $\operatorname{Tim} p=1$ was used to find the maximum HACCs when tuning different mtrys and Timps combinations. The validation accuracy of models means whether the different labeled observations were accurately classified.

$$
\text { Accuracy }=\frac{\mathrm{TP}+\mathrm{TN}}{\mathrm{TP}+\mathrm{TN}+\mathrm{FP}+\mathrm{FN}}
$$

Where TP is the number of true positives, $\mathrm{TN}$ is the number of true negatives, FP is the number of false positives, and FN is the number of false negatives. The validation accuracy was treated as final prediction accuracy of SVMs/RF classifications. Classifications with an average prediction accuracy $\geq 80 \%$ were regarded as a high accuracy classifications (HACCs); the $80 \%$ level was determined acceptable by previous ML studies (Wang et al., 2010; Liu et al., 2014; Shang and Chisholm, 2014; Zheng et al., 2014; Sacchet et al., 2015). The whole process - RF ranking of root traits in each cultivar pair, SVMs and RF classification of pairs using different $m$ trys and Timps - was repeated three times; the average accuracy with standard error was calculated. The combination of different mtrys and different Timpis generating the highest average accuracy of SVM/RF models was treated as optimal mtry and Timpi combination; the frequencies of the corresponding top five important root traits (T5IRT) from all HACCs were calculated. Because SVM models yielded higher classification accuracies than RF (Figure 1; Supplementary Figure S2), classification by RF was not pursued further. Subsequently the accuracies of SVMs models derived from Timp5 were compared to six runs of randomly selected subsets of five root traits each (R_5.1-R_5.6) to determine the benefits of root trait selection based on RF for cultivar classification.

The $\mathrm{R}$ for Windows package 'party' (v. 1.0-23) was used for RF trait ranking; the R package 'e1071' (v. 1.6-7) was used for rbf SVMs classification (data scaled), the 'randomForest' 
TABLE 2 | Abbreviation and description of 36 root traits derived either from direct measurement or from calculation after manual phenotyping of 16 European $P$. sativum cultivars.

\begin{tabular}{|c|c|c|c|}
\hline Abbreviation & Unit & Definition & Level of trait \\
\hline slatdiam2.5 & $\mathrm{mm}$ & The average diameter of single lateral root originated from 0 to $5 \mathrm{~cm}$ deep tap root & Lateral roots \\
\hline slatlth2.5 & $\mathrm{cm}$ & The average length of single lateral root originated from 0 to $5 \mathrm{~cm}$ deep tap root & \\
\hline slatsa2.5 & $\mathrm{cm}^{2}$ & The average surface area of single lateral root originated from 0 to $5 \mathrm{~cm}$ deep tap root & \\
\hline SLSRL2.5 & $\mathrm{cm} \mathrm{g}^{-1}$ & $\begin{array}{l}\text { The average specific root length (root length divided by dry biomass) of single lateral root originated } \\
\text { from } 0 \text { to } 5 \mathrm{~cm} \text { deep tap root }\end{array}$ & \\
\hline SLSRA2.5 & $\mathrm{cm}^{2} \mathrm{~g}^{-1}$ & $\begin{array}{l}\text { The average specific root area (root area divided by dry biomass) of single lateral root originated } \\
\text { from } 0 \text { to } 5 \mathrm{~cm} \text { deep tap root }\end{array}$ & \\
\hline SLTD2.5 & $\mathrm{g} \mathrm{cm}^{-3}$ & $\begin{array}{l}\text { The average tissue density (root dry biomass divided by root volume) of single lateral root originated } \\
\text { from } 0-5 \mathrm{~cm} \text { deep tap root }\end{array}$ & \\
\hline slatdw2.5 & g & The average dry weight of single lateral root originated from 0 to $5 \mathrm{~cm}$ deep tap root & \\
\hline latRL2.5 & $\mathrm{cm}$ & The length of all the lateral roots originated from 0 to $5 \mathrm{~cm}$ deep tap root & \\
\hline latRL7.5 & $\mathrm{cm}$ & The length of all the lateral roots originated from 5 to $10 \mathrm{~cm}$ deep tap root & \\
\hline latRSA2.5 & $\mathrm{cm}^{2}$ & The surface area of all the lateral roots originated from 0 to $5 \mathrm{~cm}$ deep tap root & \\
\hline latRSA7.5 & $\mathrm{cm}^{2}$ & The surface area of all the lateral roots originated from 5 to $10 \mathrm{~cm}$ deep tap root & \\
\hline latRV2.5 & $\mathrm{cm}^{3}$ & The volume of all lateral roots coming originated from 0 to $5 \mathrm{~cm}$ deep tap root & \\
\hline latRV7.5 & $\mathrm{cm}^{3}$ & The volume of all lateral roots coming originated from 5 to $10 \mathrm{~cm}$ deep tap root & \\
\hline latRDW2.5 & g & All lateral roots dry weight from 0 to $5 \mathrm{~cm}$ deep tap root & \\
\hline latRDW7.5 & g & All lateral roots dry weight from 5 to $10 \mathrm{~cm}$ deep tap root & \\
\hline latRDW & g & The dry weight of all lateral roots & \\
\hline latn2.5 & & The number of lateral roots originated from 0 to $2.5 \mathrm{~cm}$ deep tap root & \\
\hline latn5 & & The number of lateral roots originated from 2.5 to $5 \mathrm{~cm}$ deep tap root & \\
\hline latn7.5 & & The number of lateral roots originated from 5 to $10 \mathrm{~cm}$ deep tap root & \\
\hline tapdiam2.5 & $\mathrm{mm}$ & The diameter of tap root from 0 to $5 \mathrm{~cm}$ depth & Tap root \\
\hline tapdiam7.5 & $\mathrm{mm}$ & The diameter of tap root from 5 to $10 \mathrm{~cm}$ depth & \\
\hline tapTD2.5 & $\mathrm{g} \mathrm{cm}^{-3}$ & The tissue density of tap root from 0 to $5 \mathrm{~cm}$ depth & \\
\hline tapTD7.5 & $\mathrm{g} \mathrm{cm}^{-3}$ & The tissue density of tap root from 5 to $10 \mathrm{~cm}$ depth & \\
\hline tapdw2.5 & g & Tap root dry weight from 0 to $5 \mathrm{~cm}$ depth & \\
\hline tapdw7.5 & g & Tap root dry weight from 5 to $10 \mathrm{~cm}$ depth & \\
\hline $\operatorname{tapRL}$ & $\mathrm{cm}$ & Tap root length & \\
\hline tapRSA & $\mathrm{cm}^{2}$ & Tap root surface area & \\
\hline tapRV & $\mathrm{cm}^{3}$ & Tap root volume & \\
\hline tapRDW & g & Tap root dry weight & \\
\hline lateraltapRDWR & $\mathrm{g} \mathrm{g}^{-1}$ & The ratio of all lateral roots dry weight and tap root dry weight & Root system \\
\hline lateraltapSAR & $\mathrm{cm}^{2} \mathrm{~cm}^{-2}$ & The ratio of all lateral roots area to tap root area & \\
\hline totalRSA & $\mathrm{cm}^{2}$ & Total root surface area of whole root system & \\
\hline totalRL & $\mathrm{cm}$ & Total root length of whole root system & \\
\hline totalRV & $\mathrm{cm}^{3}$ & Total root volume of whole root system & \\
\hline rootdw & g & Root dry weight & \\
\hline rootdep & $\mathrm{cm}$ & Root depth & \\
\hline
\end{tabular}

package (v. 4.6-12) for RF classification. The R code used for RF root traits ranking and rbf SVMs classification can be found as Supplementary Method S3.

\section{Univariate Permutation Test}

In order to compare the efficiency between a univariate test and the combination of RF and rbf SVMs in cultivar classification, an exact permutation test (Hesterberg et al., 2005) was carried out $(\alpha=0.05)$, with both Bonferroni and fdr correction (Benjamini and Hochberg, 1995), to compare the root traits involved in each pairwise classification. The R code used can be found as Supplementary Method S4.

\section{RESULTS}

\section{RF Root Traits Selection and SVMs Classification}

The classification accuracy of SVMs multiclass classifications with and without root trait selection were 16.5 and 22.7\%, respectively (Supplementary Figure S1), thus a pairwise approach was pursued thereafter. Similarly, the number of HACCs generated from different mtrys and Timpis combinations in pairwise RF (77 HACCs with mtry $=32$, Timpis $=2$; Supplementary Figure S2) were much lower compared to the classification accuracy achieved by pairwise SVMs (see below and Figure 1). Thus, this RF/RF approach was not followed 


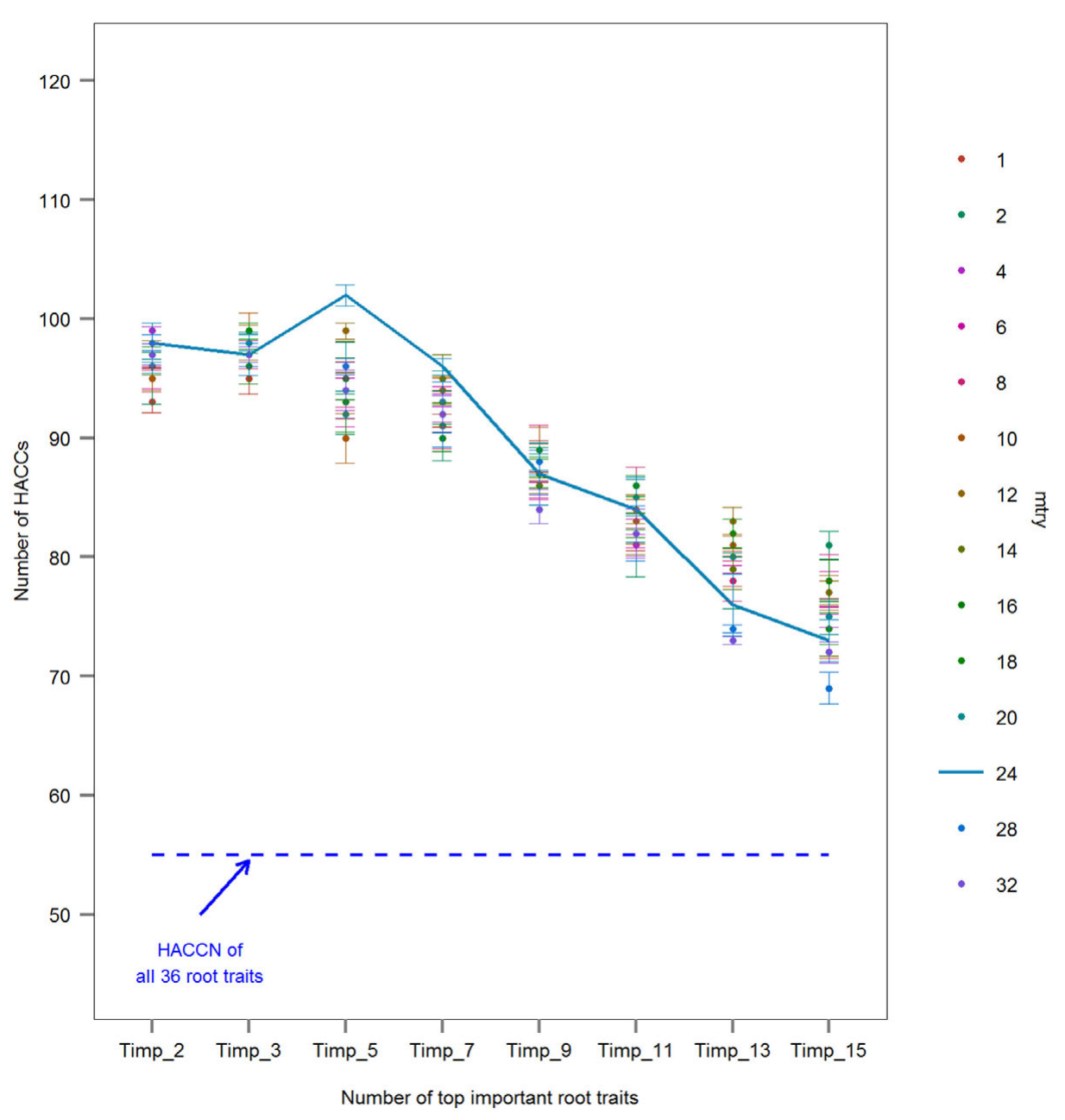

FIGURE 1 | Comparison of the number of high accuracy classifications (HACCs; prediction accuracy $\geq 80 \%$ ) using rbf SVMs models with different numbers of Pisum sativum root traits randomly chosen for each tree, $m$ trys, and different number of top important root traits, Timp_ $i=2,3,5,7,9$, $\mathbf{1 1}, \mathbf{1 3}, 15$ (mean $\pm \mathrm{SE} ; \boldsymbol{n}=\mathbf{3}$ runs). One hundred twenty pairs of 16 European $P$. sativum cultivars were analyzed. A dashed blue line represents the number of HACCs (HACCN) retrieved using all 36 root traits in SVMs classification. A line connecting HACC numbers derived by using different number of Timps at constant mtry $=24$ was added for visualization.

further but a combination of RF (for trait ranking) and SVMs (for classification) was used. Through testing a series of combinations of different mtrys and Timpis, $m$ try $=24$ and Timpi $=5$ (Timp5) generated the highest number of HACCs in pairwise comparison, 101 (averaged from three runs; 100, 101, 103 HACCs) out of 120 pairs (Figure 1). Although other combinations of mtrys and single-digit Timpis resulted in similar numbers of HACCs, the run which contained the highest number of HACCs (103) was used exemplary for further analysis (Figure 2). The least number of HACCs (54) was computed from SVMs models using all available root traits (36). The number of HACCs thus increased by $91 \%$ through root trait selection with RF and tuning SVMs to Timp5. Both single SVMs model accuracy and the total number of HACCs based on six runs of five randomly selected root traits each (R_5.1-5.6) are similar or decreased compared to using all 36 root traits (All_36) and much lower than SVMs models involving the top five important root traits (Timp_5), respectively (Figure 3).

The Timp5 in each of the 103 HACCs are ranked as 1st, 2nd, 3rd, 4th, and 5th and indicated with different colors in Figure 4 (see Supplementary Table S1 for a list of Timp5 and Supplementary Table S2 for normalized importance values of Timp5). The most frequent Timp5 of the analyzed pea cultivars in all HACCs (T5IRT) are latRSA2.5, tapdiam2.5, latn2.5, tapdw7.5, and totalRSA (see Table 2 for trait abbreviations) with proportions of 31, 23, 21, 21, and 21\%, respectively (Figure 5). The root traits measured at both $0-5$ and 5-10 cm depth (along the tap root) are lateral root surface area, tap root diameter, lateral root number, tap root dry weight (tapRDW), lateral root length, lateral root dry weight (latRDW), lateral root volume, and tap root TD. Four out of eight root trait pairs measured at $0-5 \mathrm{~cm}$ depth (i.e., latRSA2.5, tapdiam2.5, latn2.5, latn5, and tapTD2.5) 

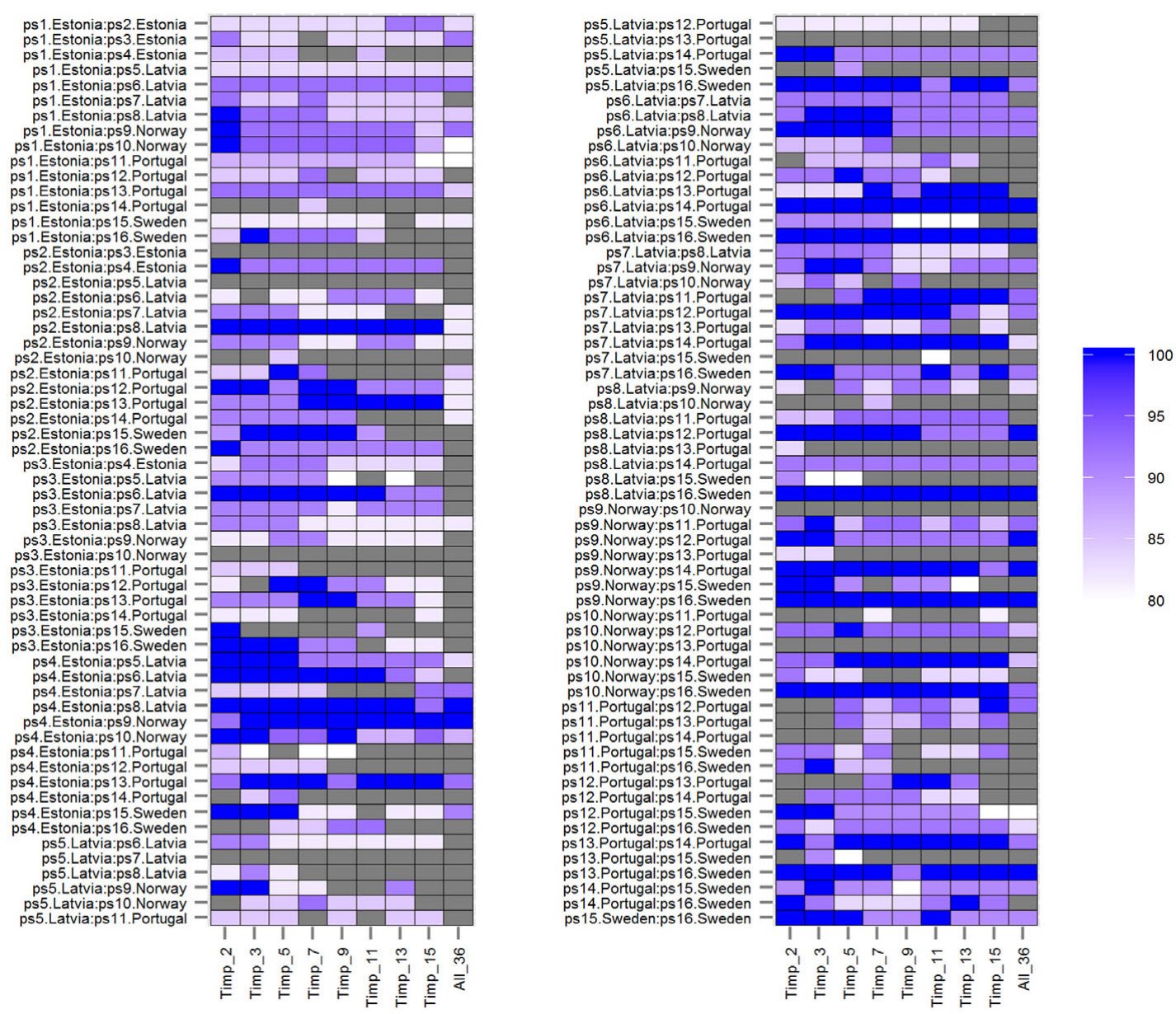

FIGURE 2 | Prediction accuracies of rbf SVMs models $(m$ try $=24)$ using different numbers of top important root traits $($ Timp $i=2,3,5,7,9,11,13$, 15) and all (36) root traits (All_36) for $\mathbf{1 2 0}$ pairwise comparisons among 16 European $\boldsymbol{P}$. sativum cultivars. Prediction accuracies from $80 \%$ (white) to $100 \%$ (blue) are shown as color gradient; lower accuracies are displayed in gray. Cultivars are listed in Table $\mathbf{1}$.

have a higher frequency among all Timp5 than corresponding ones from 5-10 cm depth along the tap root while the other four have similar frequencies (Figure $\mathbf{5}$, inset); the average frequency of Timp5 from 0-5 cm depth is 18 compared to 14 from $5-10 \mathrm{~cm}$ depth along the tap root.

In order to confirm whether conditional inference permutation test can rank root traits without bias, correlation coefficients of Timp5s are compared in different pairwise classifications. For example, Timp5 in the pair ps1.Estonia vs. ps2.Estonia (Figure 4, first line; Supplementary Tables S1 and S2) are tapRDW between $5-10 \mathrm{~cm}$ depth (tapdw7.5), lateral root try weight of $0-5 \mathrm{~cm}$ depth (latRDW2.5), total root system dry weight (rootdw), latRDW, and SRL of lateral roots at $0-5 \mathrm{~cm}$ depth (sSRL2.5). In this pair, the highest Pearson correlation between the most important root trait tapdw7.5 (ranked 1st) and the other four traits is 0.52 (Figure 6; see Supplementary Figure S3 for Spearman correlation); tapRDW, which has a very high correlation coefficient of 0.89 with tapdw7.5, is not involved in the Timp5 of the pair ps1.Estonia vs. ps2.Estonia. Rootdw and latRDW, which are highly correlated with a Pearson coefficient of 1 , ranked as 3rd and 4th in the classification of ps1.Estonia and ps2.Estonia (Figure 6). In another example (ps1.Estonia vs. ps7.Latvia), both rootdw and latRDW are among the Timp5 but rootdw is ranked 1st while latRDW is ranked 5th (Figure 4; Supplementary Tables S1 and S2).

The highest correlation coefficient among T5IRTs was 0.93 (Pearson correlation, Figure 6; see Supplementary Figure S3 for Spearman correlations) between latRSA2.5 and totalRSA while the lowest was 0.31 (Pearson) between tapdw7.5 and lateral root number at $0-2.5 \mathrm{~cm}$ depth (latn2.5). The frequencies of latRSA2.5 and totalRSA among T5IRTs (Figure 5) are among the highest with 32 and 22, respectively, while they only appear nine times simultaneously in the same pairwise classification.

\section{Permutation Test Comparing the Difference of the Mean of Single Root Trait}

Comparing the efficiency of ML techniques conducted by RF and SVMs with a univariate permutation test, only $46.6 \%$ 

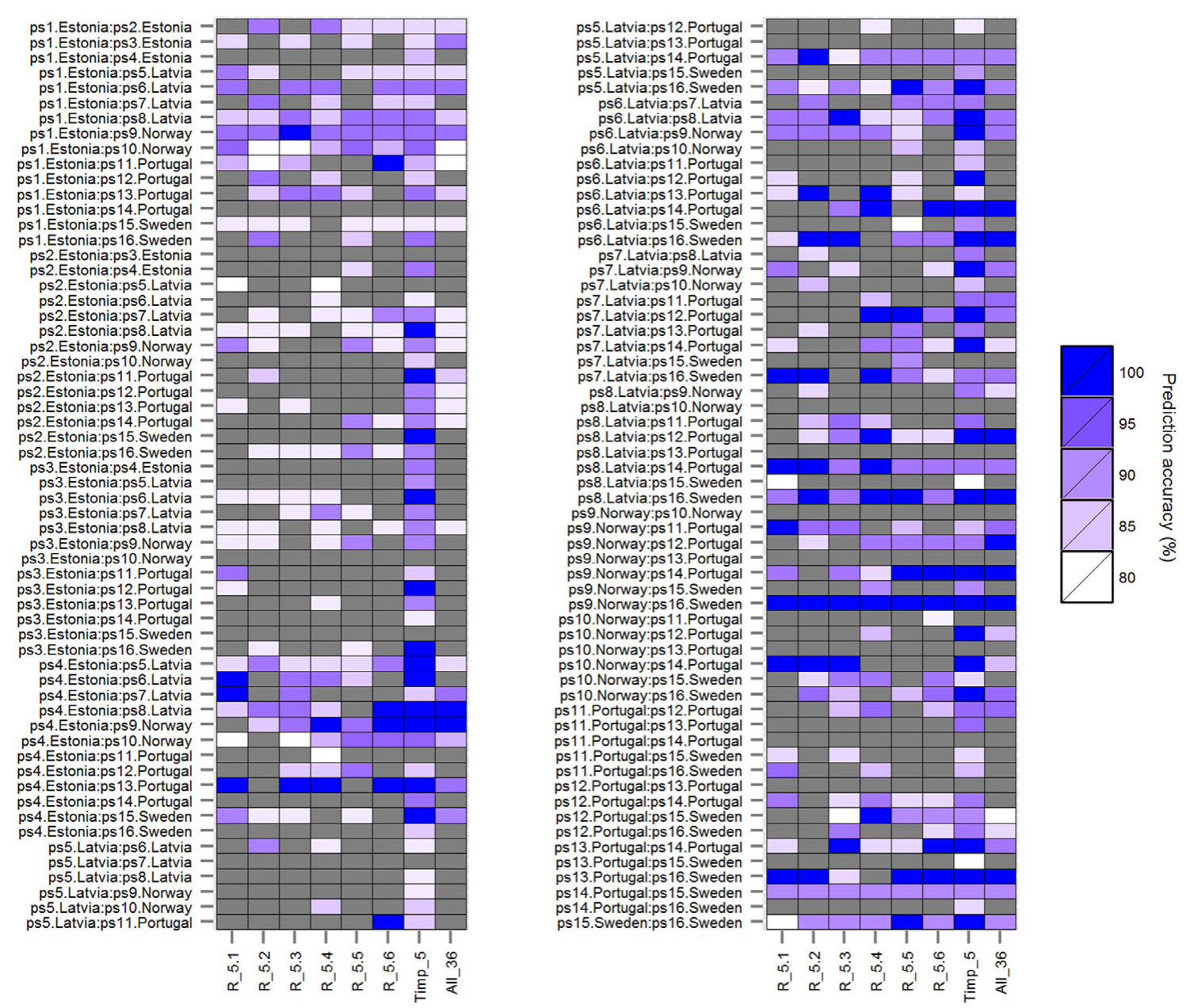

FIGURE 3 | Prediction accuracies of rbf SVMs models $(m t r y=24)$ using five randomly selected root traits each in six runs $\left(R \_5.1, R \_5.2, R \_5.3, R \_5.4\right.$, $R \_5.5$, and $R_{-}$5.6) compared to prediction accuracies using top five important root traits (Timp_5), and all (36) root traits (All_36) for 120 pairwise comparisons among 16 European $\boldsymbol{P}$. sativum cultivars. Prediction accuracies from $80 \%$ (white) to $100 \%$ (blue) are shown as color gradient; lower accuracies are displayed in gray. Cultivars are listed in Table $\mathbf{1}$.

(Bonferroni-corrected) and 47.5\% (fdr-corrected) of HACCs (based on Timp5) have significantly different root traits. Significantly different root traits in univariate permutation tests can be found in (supplementary) figures (Figure 7, with Bonferroni correction; Supplementary Figure S4, with fdr correction). SVMs were not always superior to univariate permutation test without root traits selection: classification accuracies of several pairwise SVMs classifications involving significantly different root traits in univariate permutation test were lower than $80 \%$ [see, e.g., ps11.Portugal vs. ps16.Sweden (Figure 7; Supplementary Figure S4)].

Three examples are given to visualize the mean difference of root traits in pairwise comparisons. There are significant different root traits between ps1.Estonia vs. ps8.Latvia and the cultivars are also classified with high accuracy (92.3\%; Figure 8). In contrast, cultivars ps3.Estonia vs. ps9.Norway are classified with high accuracy (90.9\%), however, without any significant root traits identified by univariate permutation test (Supplementary
Figure S5). There are (visibly) no significant different root traits between cultivars ps1.Estonia vs. ps14.Portugal and they are not accurately classified either - accuracy 69.2\% (Supplementary Figure S6). The most significantly different root traits (the lowest $p$ value in univariate permutation test) can be different from the most important root traits (ranked by RF) in each pairwise classification, e.g., Timp5 in the pair ps3.Estonia vs. ps9.Norway are tapdw7.5, tapRDW, rootdw, latn5, and latRDW while the rank order based on $p$ values from permutation test changed to latn5, tapdw7.5, tapRDW, latRDW, and rootdw. No tied importance values of Timp5, indicating higher ranking root traits are more important in RF, have been found.

\section{DISCUSSION}

Machine learning algorithms are promising statistical tools to assist humans in the analysis of complex data sets and 


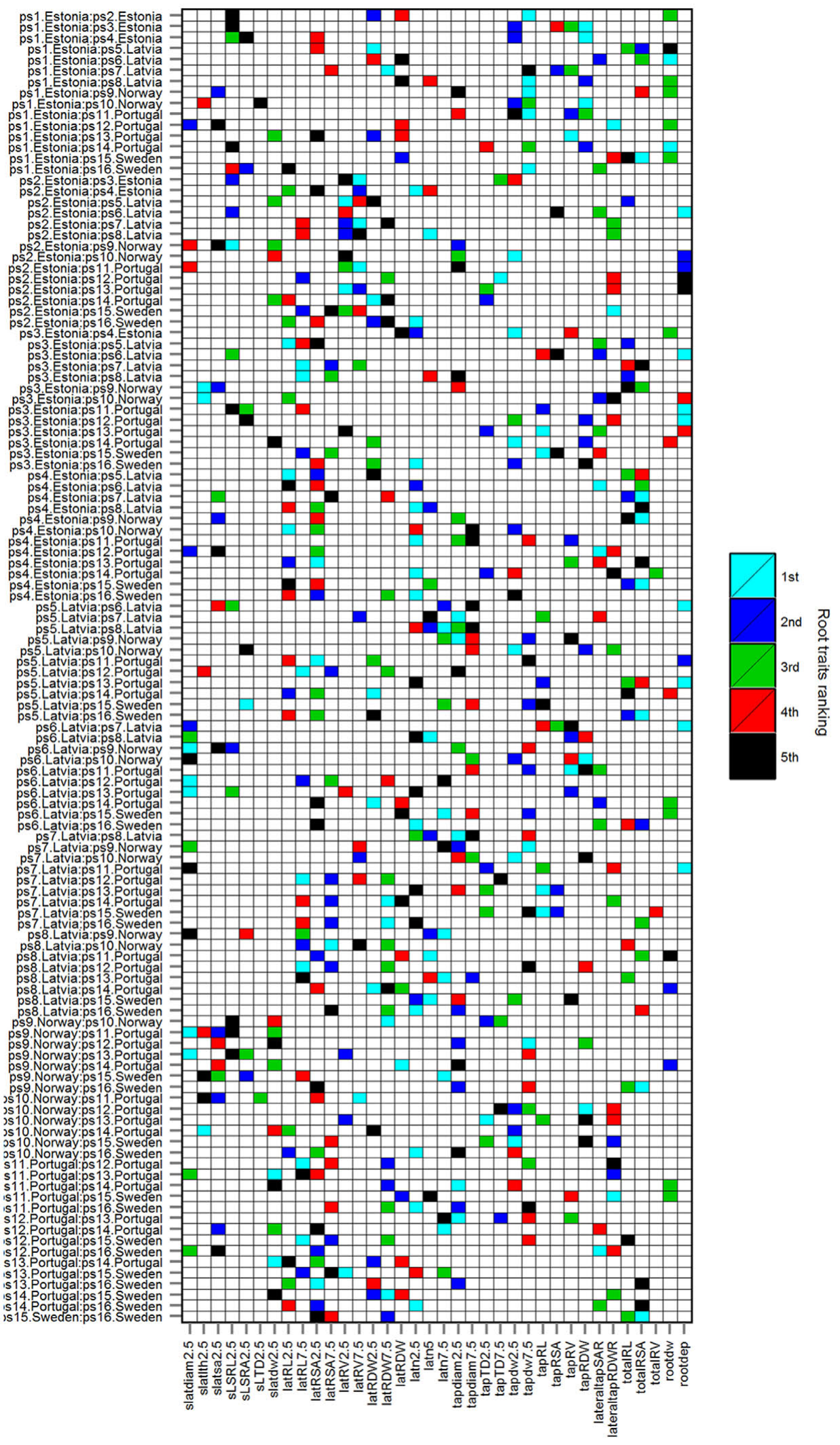

FIGURE 4 | Top five important root traits (Timp5) ranked as 1st, 2nd, 3rd, 4th, and $5^{\text {th }}$ in each of 103 HACCs; rbf SVMs prediction accuracy $\geq 80 \%$. Cultivars are listed in Table 1, root trait abbreviations in Table 2. 


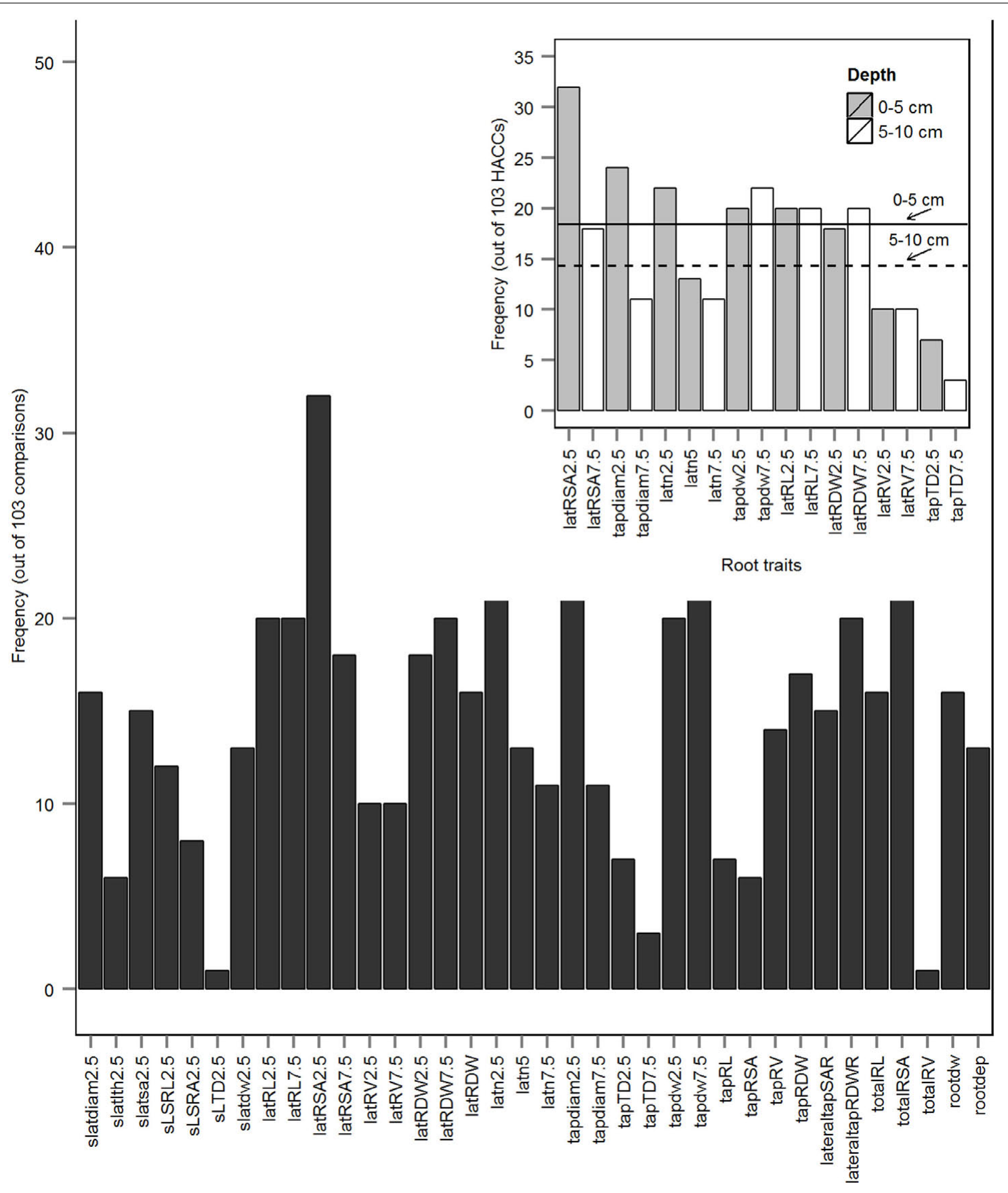

Root traits

FIGURE 5 | Frequencies of top five important root traits (Timp5) in 103 high accuracy classifications (HACCs; rbf SVMs prediction accuracy $\geq 80 \%$ ) identified out of 120 pairwise comparisons among 16 European $P$. sativum cultivars. The inset illustrates the frequencies of root traits from 0 to $5 \mathrm{~cm}$ depth along the tap root (gray bars) and from 5 to $10 \mathrm{~cm}$ depth (white bars), respectively; a solid line indicates the average number of Timp5 from 0 to $5 \mathrm{~cm}$ depth, a dashed line indicates the average number of Timp5 from 5 to $10 \mathrm{~cm}$ depth tap root. Root trait abbreviations are listed in Table 2.

started to be widely used in many research fields including (plant) genomics/proteomics (Ma et al., 2014; Libbrecht and Noble, 2015). To the best of our knowledge, they have been only applied twice on RSA differentiation yet (Zhong et al., 2009; Iyer-Pascuzzi et al., 2010). This is surprising because as new technologies for generating large plant phenotypical data sets emerge, demand will drastically increase for new statistical techniques. Phenotyping is estimated in becoming the major operational bottleneck in limiting the power of genetic analysis and genomic prediction (Rahaman et al., 2015). Data 


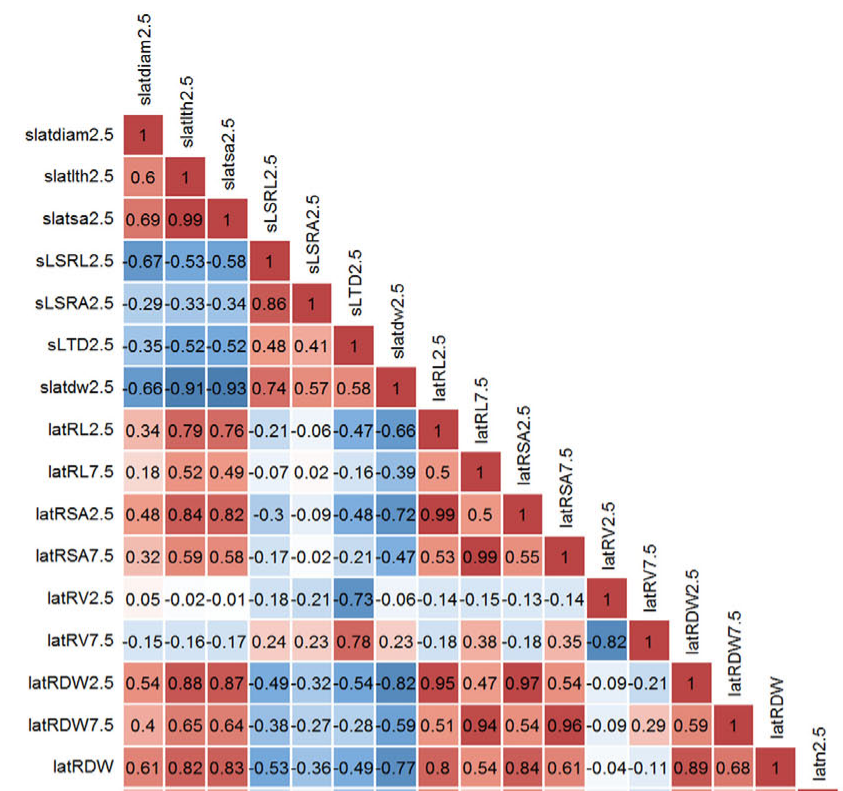

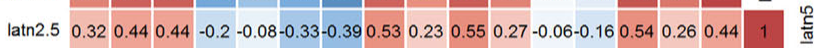

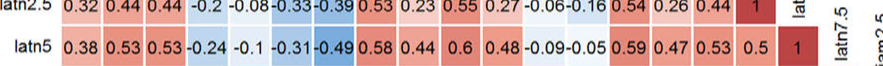

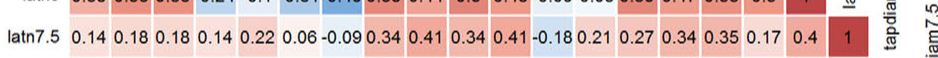

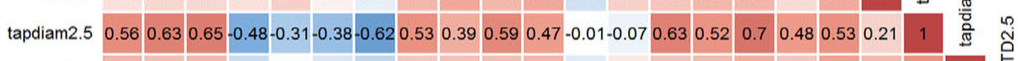

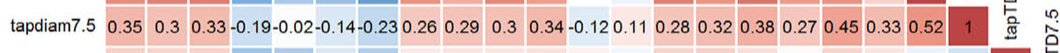

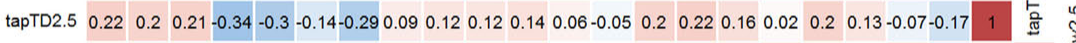

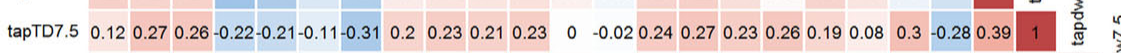

\begin{tabular}{ll|l|l|l|l|l|l|l|l|l|l|l|l|l|l|l|l|l|l|l|l|l|l|l|l|l} 
tapdw2.5 & 0.59 & 0.59 & 0.62 & -0.54 & -0.34 & -0.35 & -0.6 & 0.43 & 0.41 & 0.5 & 0.48 & 0.03 & -0.05 & 0.58 & 0.56 & 0.62 & 0.36 & 0.52 & 0.24 & 0.69 & 0.43 & 0.54 & 0.33 & 1 & $\frac{3}{5}$ \\
\hline
\end{tabular}

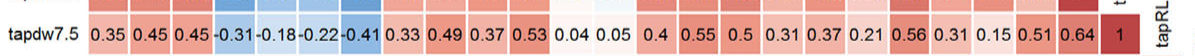

tapRL - $0.11-0.07-0.080 .180 .24 \quad 0.07 \quad 0.18-0.020 .08-0.020 .08-0.110 .17-0.080 .02-0.05-0.01-0.080 .12-0.130 .290 .01-0.130 .030 .15 \quad 1 \quad \frac{1}{\pi}$

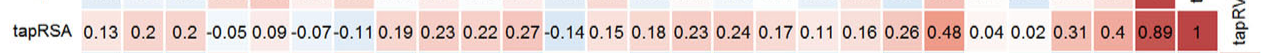

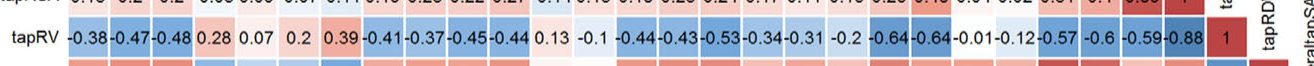

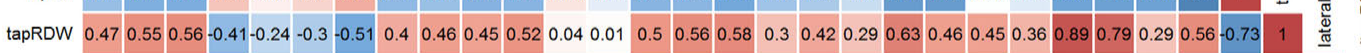

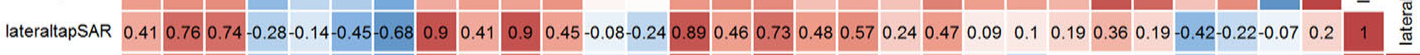

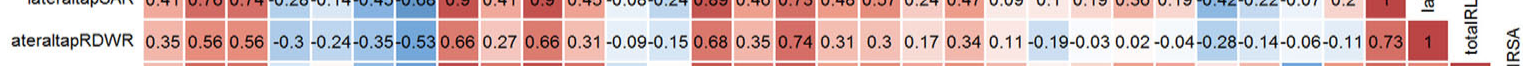

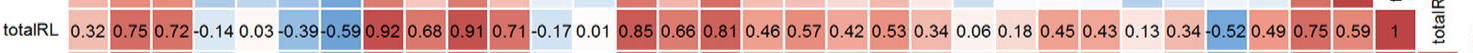

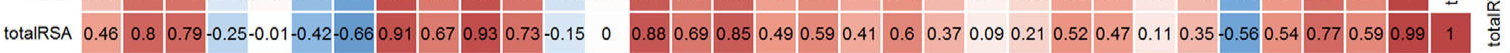

totalRV $-0.04-0.11-0.1-0.13-0.22-0.52-0.03-0.22-0.26-0.23-0.27 \quad 0.77-0.69-0.16-0.2-0.21-0.12-0.11-0.21-0.21-0.260 .06-0.04-0.15-0.17-0.34-0.430 .44-0.26-0.03-0.06-0.37-0.35 \quad 1 \quad \frac{3}{\circ}$

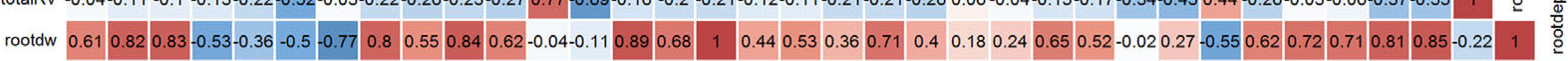

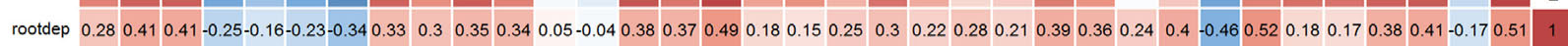

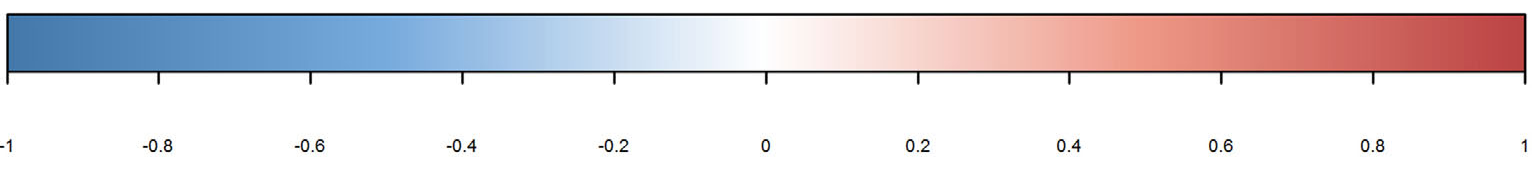

FIGURE 6 | Pearson correlation coefficients among 36 root traits determined on mature plants of 16 European $P$. sativum cultivars ( $n=5-7)$. Positive correlations are visualized by a red color gradient, negative correlations by a blue color gradient. Root trait abbreviations are listed in Table 2.

complexity of particular sets of traits is generally high, especially in root systems where the developments causing a specific architecture, and the physiology and performance of individual root segments/units within the branched root system are not well understood yet.
So far, most of the techniques developed for RSA phenotyping involve the of use seedlings (Kuijken et al., 2015). Although there are examples in which the early stage root phenotype has predictive value for later developmental stages (Tuberosa et al., 2002), the seedling root phenotype may not always be 


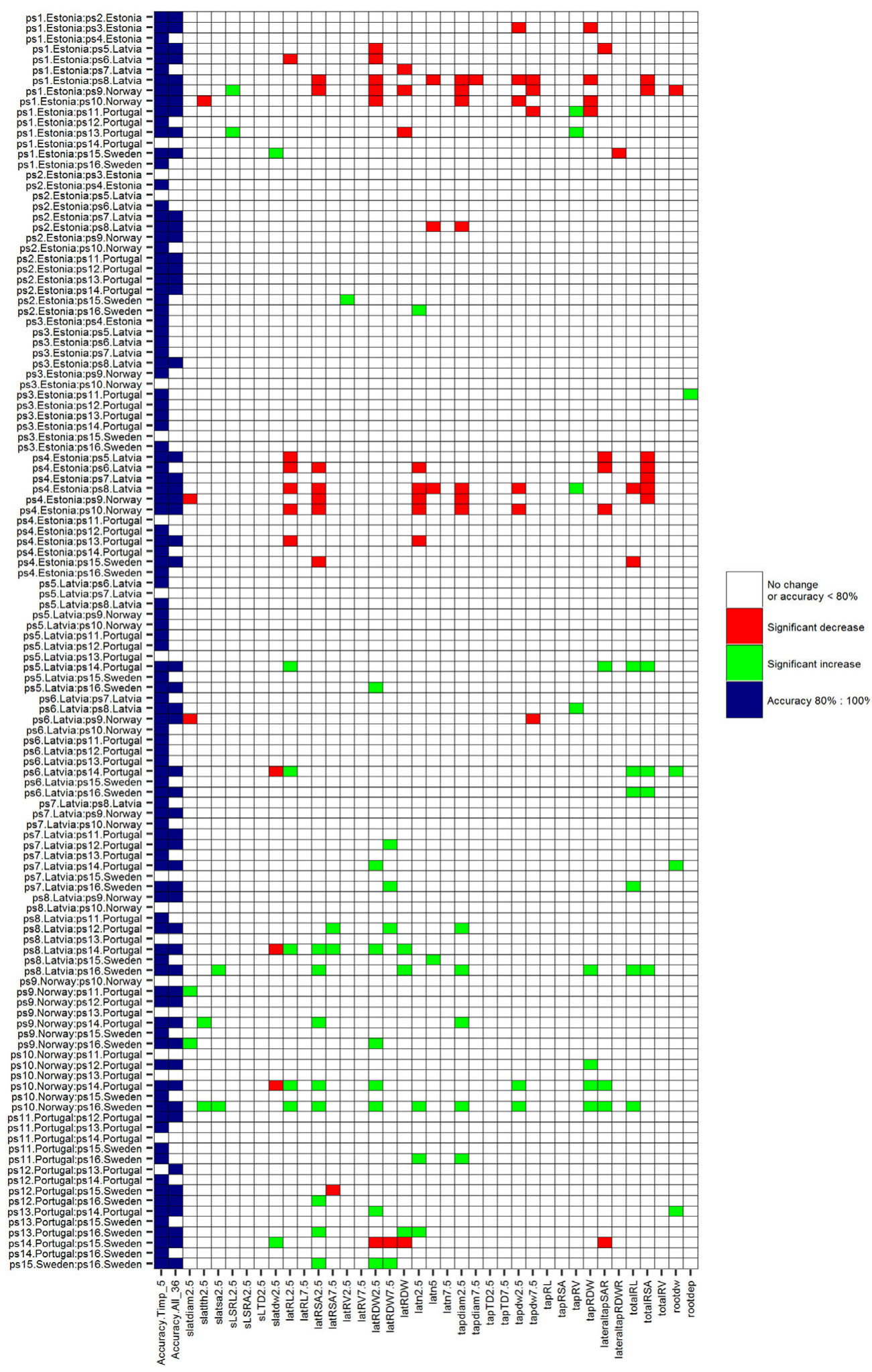

FIGURE $7 \mid P$-values of univariate permutation tests (Bonferroni-corrected) comparing the difference of means of each single root trait between 16 mature $\boldsymbol{P}$. sativum L. cultivars in each pair. Significantly $(P$-values $<0.05)$ increased root traits are marked green, significant decreased root traits are marked red, $P \geq 0.05$ white; accuracy. Timp_5 and accuracy. All_36 (light blue) indicating HACCs with Timp5/all root traits involved in SVMs, respectively. Cultivars are listed in Table 1, root trait details in Table 2. 


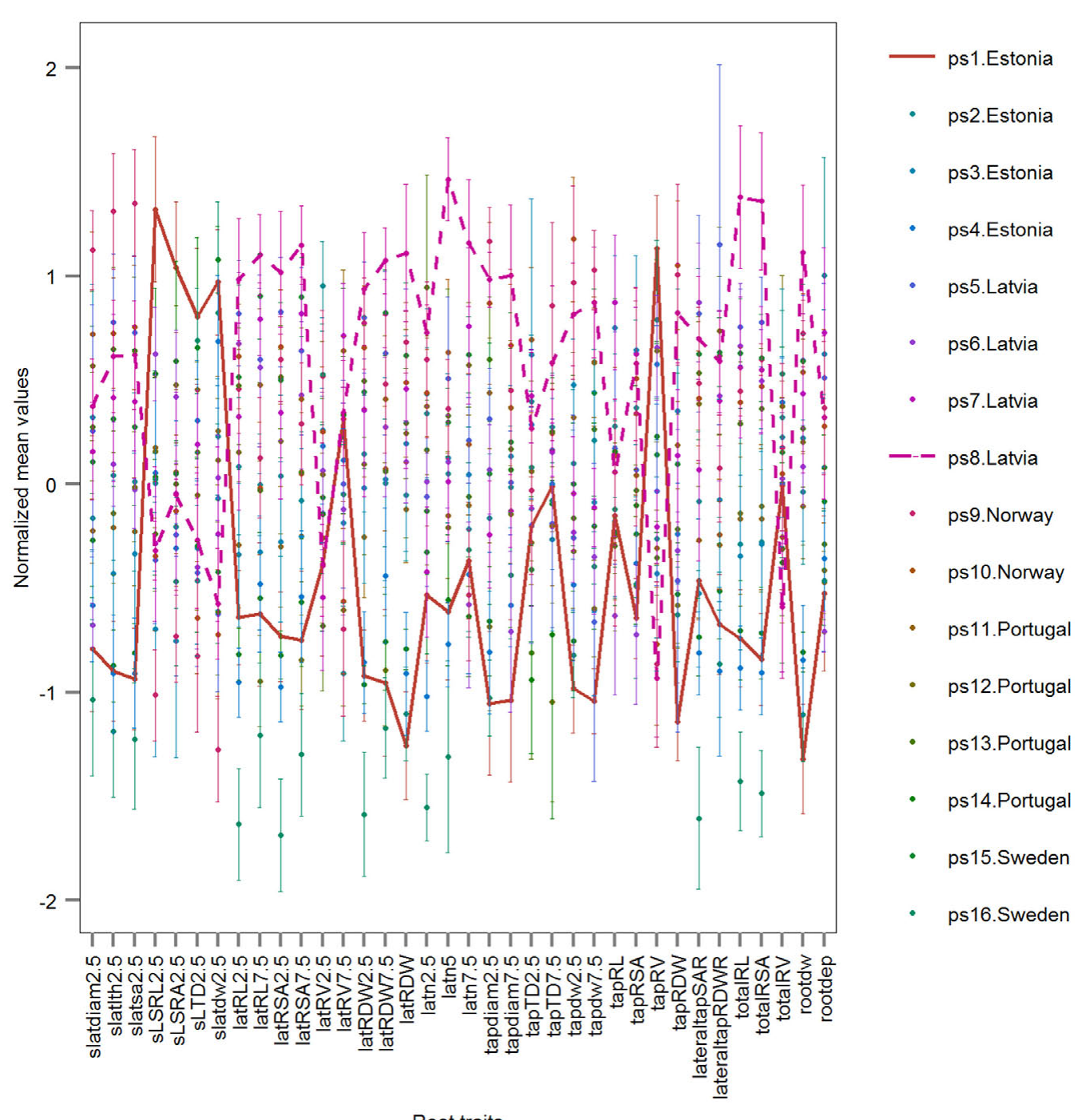

FIGURE 8 | Normalized root traits determined on mature plants of 16 European $P$. sativum cultivars (mean \pm SE; $\boldsymbol{n}=\mathbf{5 - 7}$ ). Two horizontal lines visualize traits of the cultivars ps1.Estonia (solid) and ps8. Latvia (dashed). Cultivars are listed in Table 1, root trait abbreviations in Table 2.

representative of the mature plant (Watt et al., 2013). Because replicate numbers from manual phenotyping of mature root systems are limited but mature root systems often have a higher complexity, adapted statistical methods need to be developed to make full use of data sets. Here we applied combined ML algorithms with unbiased variable importance measure for the first time successfully, to the best of our knowledge, on a small RSA/root morphology data set manually derived from 97 mature plants of 16 European pea cultivars. The importance of 36 root traits was measured and ranked in RF. Pairwise classifications were analyzed either by SVMs based on a Gaussian radial basis kernel function (rbf SVMs) or by RF (standard algorithm) with the RF-identified top ranking root traits. The overall accuracy of models was cross-validated. The combination of SVMs and RF improved the classification accuracy - confirming earlier results by Löw et al. (2012) in remote sensing.
When compared to classical statistical tools, our results demonstrated that all pairwise classifications with significant root traits from univariate permutation test belong to HACCs with Timp5, however, almost half of HACCs derived from Timp5 don't have any significantly different root traits. This points to the advantages of combining RF and SVMs in root traits importance measure and cultivar classification. Besides robustness to noises, RF considers both the influence of single variables separately and the multivariate interactions with other variables, which make this advanced ML approach more efficient, accurate, and reliable (Breiman, 2001; Zhu et al., 2012). Among the HACCs with significantly different root traits, the ranking of top five important root traits (Timp5) was not matched by $p$ values from univariate permutation test, i.e., the most significantly different root traits differ with the most important root traits identified by pairwise classification. This might be due to that SVMs classification 
concerns more about parameters (root traits) involved in the SVMs models while traditional multi/univariate analyses focus more on differences of specific root traits between two groups (Gaonkar et al., 2015). We conclude that the combination of RF root traits selection and SVMs classification can make full use of all possible information of root traits in pea cultivars' classification.

Our results clearly demonstrated the importance of selecting important root traits by RF to obtain an efficient classification based on RSA among dicot crop cultivars. SVMs models using all available traits or including five randomly selected root traits (R_5) were not able to increase the overall accuracy, which confirmed the necessity of root traits selection through RF in cultivar differentiation. This finding is in accordance with previous ML approaches in other scientific fields (Wang et al., 2010; Löw et al., 2012; Liu et al., 2014). The improved accuracy probably benefits from alleviating the 'curse of dimensionality' through root traits selection, removing non-informative signals (Chu et al., 2012). Thus, we can show that the identification of a few important root traits, in our case five, significantly increases the classification accuracy. While we did not find any single pea root trait that was always more important than others in all HACCs, a more targeted cultivar differentiation and trait selection for breeding can be obtained when focusing on root traits with highest frequency among T5IRTs. The most frequent T5IRT among the tested pea cultivars was the surface area of all lateral roots originating at the tap root between 0-5 cm (latRSA2.5) - appearing in more than one third of the pairwise comparisons. Distinguishing cultivars based on latRSA2.5 value can have important ecological effects: greater latRSA2.5 implicates more absorptive lateral root surface area in the topsoil and thus the potential for enhanced $\mathrm{P}$ or topsoil water foraging. Lower latRSA2.5 values means that plants are possibly privileging deep soil exploration (Miguel et al., 2015) with potential influences on drought tolerance or performance in low input agriculture (Bonser et al., 1996). Another frequent T5IRT in pea was latn2.5, the number of laterals originating at the tap root between $0-5 \mathrm{~cm}$, which is somehow comparable to the trait 'whorl numbers' of Phaseolus vulgaris seedlings (Miguel et al., 2013). Miguel and colleagues could show that common bean genotypes with greater whorl numbers accumulated up to $60 \%$ more biomass under low-phosphorus conditions.

Completely intact root systems can hardly be collected by destructive harvesting methods, especially of mature plants with deeper root systems grown in the field; similar, lateral root traits are likely more affected by destructive sampling, e.g., by root tip shedding, than tap root traits. RSA information retrieved from top soil layers is thus likely more accurate (Miguel, 2012). Interestingly, the number of Timp5 derived from $0-5 \mathrm{~cm}$ depth of the pea tap root were more frequent than the ones originating from $5-10 \mathrm{~cm}$ depth, indicating that root traits from the top of the tap root have a greater potential to differentiate pea cultivars. This knowledge is already utilized by 'shovelomics' approaches, which only excavate the root crown of mature plants for phenotypical analysis (Trachsel et al., 2011; Bucksch et al., 2014). Our findings thus provide additional evidence that shovelomics can be considered an informative field-based high-throughput phenotyping approach due to the strong contribution of topsoil root traits to cultivar distinction.

Root system depth and average radius were previously identified as frequently top-ranked root traits in linear SVMs classification to distinguish different rice genotypes (IyerPascuzzi et al., 2010). In our study the top two frequently important root traits were latRSA2.5 and tapdiam 2.5 while root system depth (rootdep) was much less frequently present in Timp5. However, the top important root traits identified by Iyer-Pascuzzi et al. (2010) might be subject to change as the used ranking method was recently deemed biased (Gaonkar and Davatzikos, 2013). However, the difference of key root traits is likely also related to species-specific differences between rice and pea, but also the differences in growth stages (juvenile vs. mature), media (gel vs. sand), and analyzing methods (see "Discussion" above).

Correlation among traits is generally considered as an indication of their redundancy for classification. However, they may still provide complementary information and an otherwise inconclusive variable can provide a significant performance in combination with others (Guyon and Elisseeff, 2003). The correlation of Timp5 from all pairwise classifications varied greatly in this study: On the one hand, highly correlated root traits were not always top-ranked; on the other hand, root traits that were highly correlated with the most important Timp could even not be important at all in our study. The correlation variance of Timp5 thus confirms the unbiased root traits importance measure through conditional inference permutation test - increasing data interpretability.

\section{CONCLUSION}

The accurate classification of $86 \%$ (103 of 120) genotype pairs of pea indicated that most of the studied cultivars could be well differentiated by using a few most distinguishing root traits, as selected through RF. This implies that past culturing did not lead to a major loss of RSA variability of the studied European pea cultivars. Breeders are envisioned to work more effectively in future breeding programs by knowing distinguishing (pea) root traits in advance (Manavalan et al., 2010). In specific, pairwise classification approaches can help breeders to make informed decisions on cultivars selection for crossing. Powerful statistical approaches are essential to make use of the increasing amount of phenotyping information available, integrating the complex trait sets. In particular, this study showed that combining RF with rbf SVMs for variable selection and group classification, respectively, can overcome problems in applying ML approaches on data sets characterized by a rather low signal-to-noise ratio. Thus, ML methods are generally envisioned to make plant phenotypical data analyses more effectively, robust and comprehensive. However, our experiment under standardized conditions might have caused the loss of root traits adaptive to local environmental conditions. Thus, further ML-supported analysis of field-derived root phenotypes under varying environments are urgently needed, selecting genotypes that feature specific sets of traits 
facilitating plant performance under local edaphic and climatic conditions. Advanced methods must be urgently developed in order to facilitate the phenotyping of mature root systems under realistic growing conditions.

\section{AUTHOR CONTRIBUTIONS}

JZ, GB, and BR conceived and planned the experiment; JZ and BR performed the experiment; JZ analyzed the data; all authors jointly wrote the manuscript.

\section{FUNDING}

This project received funding from the European Union's Seventh Framework Program for research, technological

\section{REFERENCES}

Alves-Carvalho, S., Aubert, G., Carrère, S., Cruaud, C., Brochot, A. L., Jacquin, F., et al. (2015). Full-length de novo assembly of RNA-seq data in pea (Pisum sativum L.) provides a gene expression atlas and gives insights into root nodulation in this species. Plant J. 84, 1-19. doi: 10.1111/tpj.12967

Annicchiarico, P., and Iannucci, A. (2008). Breeding strategy for faba bean in southern europe based on cultivar responses across climatically contrasting environments. Crop Sci. 48, 983-991. doi: 10.2135/cropsci2007.09.0501

Ball, T. M., Stein, M. B., Ramsawh, H. J., Campbell-Sills, L., and Paulus, M. P. (2014). Single-subject anxiety treatment outcome prediction using functional neuroimaging. Neuropsychopharmacology 39, 1254-1261. doi: 10.1038/npp. 2013.328

Benjamini, Y., and Hochberg, Y. (1995). Controlling the false discovery rate: a practical and powerful approach to multiple testing. J. R. Stat. Soc. Ser. B 57, 289-300.

Berger, B., Parent, B., and Tester, M. (2010). High-throughput shoot imaging to study drought responses. J. Exp. Bot. 61, 3519-3528. doi: 10.1093/jxb/erq201

Bonser, A. M., Lynch, J., and Snapp, S. (1996). Effect of phosphorus deficiency on growth angle of basal roots in Phaseolus vulgaris. New Phytol. 132, 281-288. doi: 10.1111/j.1469-8137.1996.tb01847.x

Breiman, L. (2001). Random forests. Mach. Learn. 45, 5-32. doi: 10.1023/A: 1017934522171

Bucksch, A., Burridge, J., York, L. M., Das, A., Nord, E., Weitz, J. S., et al. (2014). Image-based high-throughput field phenotyping of crop roots. Plant Physiol. 166, 470-486. doi: 10.1104/pp.114.243519

Caringella, M. A., Bongers, F. J., and Sack, L. (2015). Leaf hydraulic conductance varies with vein anatomy across Arabidopsis thaliana wild-type and leaf vein mutants. Plant Cell Environ. 38, 2735-2735. doi: 10.1111/pce.12584

Cernay, C., Ben-Ari, T., Pelzer, E., Meynard, J.-M., and Makowski, D. (2015). Estimating variability in grain legume yields across Europe and the Americas. Sci. Rep. 5:11171. doi: 10.1038/srep11171

Chu, C., Hsu, A.-L., Chou, K.-H., Bandettini, P., Lin, C., Initiative, et al. (2012). Does feature selection improve classification accuracy? Impact of sample size and feature selection on classification using anatomical magnetic resonance images. Neuroimage 60, 59-70. doi: 10.1016/j.neuroimage.2011.11.066

Cortes, C., and Vapnik, V. (1995). Support-vector networks. Mach. Learn. 20, 273-297. doi: 10.1007/BF00994018

Cramer, G. R., Ergül, A., Grimplet, J., Tillett, R. L., Tattersall, E. A., Bohlman, M. C., et al. (2007). Water and salinity stress in grapevines: early and late changes in transcript and metabolite profiles. Funct. Integr. Genomics 7, 111-134. doi: 10.1007/s10142-006-0039-y

da Costa, L. L., Delcroix, M., Dalla Costa, E. R., Prestes, I. V., Milano, M., Francis, S. S., et al. (2015). A real-time PCR signature to discriminate between tuberculosis and other pulmonary diseases. Tuberculosis 95, 421-425. doi: 10 . 1016/j.tube.2015.04.008 development and demonstration under grant agreement no 613781 (EUROLEGUME).

\section{ACKNOWLEDGMENTS}

We kindly thank all donors for the genetic material; Ina Alsiņa, Latvia and Aleš Látr, Czech Republic kindly proved the rhizobia and mycorrhizal inoculum, respectively. Michael J. Bambricks' help during the harvest and root system dissection was essential.

\section{SUPPLEMENTARY MATERIAL}

The Supplementary Material for this article can be found online at: http://journal.frontiersin.org/article/10.3389/fpls.2016.01864/ full\#supplementary-material

Díaz-Uriarte, R., and De Andres, S. A. (2006). Gene selection and classification of microarray data using random forest. BMC Bioinformatics 7:3. doi: 10.1186/ 1471-2105-7-3

EU (2013). The Environmental Role of Protein Crops in the New Common Agricultural Policy: Agricultural and Rural Development: Directorate General for Internal Policies, Policy Department B: Structural and Cohesion Policies. Brussels: European Parliament, 119.

FAOSTAT (2014). Food and Agriculture Organization of the United Nations. Available at: http://faostat3.fao.org/home/E

Fiorani, F., and Schurr, U. (2013). Future scenarios for plant phenotyping. Annu. Rev. Plant Biol. 64, 267-291. doi: 10.1146/annurev-arplant-050312-120137

Gaonkar, B., and Davatzikos, C. (2013). Analytic estimation of statistical significance maps for support vector machine based multi-variate image analysis and classification. Neuroimage 78, 270-283. doi: 10.1016/j.neuroimage. 2013.03.066

Gaonkar, B., Shinohara, R. T., Davatzikos, C., Alzheimers Disease, and Neuroimaging Initiative. (2015). Interpreting support vector machine models for multivariate group wise analysis in neuroimaging. Med. Image Anal. 24, 190-204. doi: 10.1016/j.media.2015.06.008

Gilbert, M. E., Zwieniecki, M. A., and Holbrook, N. M. (2011). Independent variation in photosynthetic capacity and stomatal conductance leads to differences in intrinsic water use efficiency in 11 soybean genotypes before and during mild drought. J. Exp. Bot. 62, 2875-2887. doi: 10.1093/jxb/ erq461

Gorbe, E., and Calatayud, A. (2012). Applications of chlorophyll fluorescence imaging technique in horticultural research: a review. Sci. Hortic. 138, 24-35. doi: 10.1016/j.scienta.2012.02.002

Gowin, J. L., Ball, T. M., Wittmann, M., Tapert, S. F., and Paulus, M. P. (2015). Individualized relapse prediction: personality measures and striatal and insular activity during reward-processing robustly predict relapse. Drug Alcohol Depend. 152, 93-101. doi: 10.1016/j.drugalcdep.2015.04.018

Grady, K. C., Laughlin, D. C., Ferrier, S. M., Kolb, T. E., Hart, S. C., Allan, G. J., et al. (2013). Conservative leaf economic traits correlate with fast growth of genotypes of a foundation riparian species near the thermal maximum extent of its geographic range. Funct. Ecol. 27, 428-438. doi: 10.1111/1365-2435. 12060

Guo, D., Xia, M., Wei, X., Chang, W., Liu, Y., and Wang, Z. (2008). Anatomical traits associated with absorption and mycorrhizal colonization are linked to root branch order in twenty-three Chinese temperate tree species. New Phytol. 180, 673-683. doi: 10.1111/j.1469-8137.2008.02573.x

Guyon, I., and Elisseeff, A. (2003). An introduction to variable and feature selection. J. Mach. Learn. Res. 3, 1157-1182.

Hargreaves, C. E., Gregory, P. J., and Bengough, A. G. (2009). Measuring root traits in barley (Hordeum vulgare ssp. vulgare and ssp. spontaneum) seedlings using gel chambers, soil sacs and X-ray microtomography. Plant Soil 316, 285-297. doi: $10.1007 /$ s11104-008-9780-4 
Hartmann, A., Czauderna, T., Hoffmann, R., Stein, N., and Schreiber, F. (2011). HTPheno: an image analysis pipeline for high-throughput plant phenotyping. BMC Bioinformatics 12:148. doi: 10.1186/1471-2105-12-148

Hesterberg, T., Moore, D. S., Monaghan, S., Clipson, A., and Epstein, R. (2005). Bootstrap methods and permutation tests. Introduction Pract. Stat. 5, 1-70.

Hsu, C.-W., Chang, C.-C., and Lin, C.-J. (2010). A Practical Guide to Support Vector Classification. Taipei: National Taiwan University.

Hu, X., Tanaka, A., and Tanaka, R. (2013). Simple extraction methods that prevent the artifactual conversion of chlorophyll to chlorophyllide during pigment isolation from leaf samples. Plant Methods 9:19. doi: 10.1186/1746-4811-9-19

Hund, A., Reimer, R., and Messmer, R. (2011). A consensus map of QTLs controlling the root length of maize. Plant Soil 344, 143-158. doi: 10.1007/ s11104-011-0735-9

Iqbal, Y., and Lewandowski, I. (2014). Inter-annual variation in biomass combustion quality traits over five years in fifteen Miscanthus genotypes in south Germany. Fuel Process. Technol. 121, 47-55. doi: 10.1016/j.fuproc.2014. 01.003

Iyer-Pascuzzi, A. S., Symonova, O., Mileyko, Y., Hao, Y., Belcher, H., Harer, J., et al. (2010). Imaging and analysis platform for automatic phenotyping and trait ranking of plant root systems. Plant Physiol. 152, 1148-1157. doi: 10.1104/pp. 109.150748

Jezierny, D., Mosenthin, R., and Bauer, E. (2010). The use of grain legumes as a protein source in pig nutrition: a review. Anim. Feed Sci. Technol. 157, 111-128. doi: 10.1016/j.anifeedsci.2010.03.001

Jia, Y., Gray, V. M., and Straker, C. J. (2004). The influence of Rhizobium and arbuscular mycorrhizal fungi on nitrogen and phosphorus accumulation by Vicia faba. Ann. Bot. 94, 251-258. doi: 10.1093/aob/mch135

Jiang, H., Deng, Y., Chen, H.-S., Tao, L., Sha, Q., Chen, J., et al. (2004). Joint analysis of two microarray gene-expression data sets to select lung adenocarcinoma marker genes. BMC Bioinformatics 5:81. doi: 10.1186/1471-2105-5-81

Kashiwagi, J., Krishnamurthy, L., Crouch, J., and Serraj, R. (2006). Variability of root length density and its contributions to seed yield in chickpea (Cicer arietinum L.) under terminal drought stress. Field Crops Res. 95, 171-181. doi: 10.1016/j.fcr.2005.02.012

Kashiwagi, J., Krishnamurthy, L., Upadhyaya, H. D., Krishna, H., Chandra, S., Vadez, V., et al. (2005). Genetic variability of drought-avoidance root traits in the mini-core germplasm collection of chickpea (Cicer arietinum L.). Euphytica 146, 213-222. doi: 10.1007/s10681-005-9007-1

Kohavi, R. (1995). "A study of cross-validation and bootstrap for accuracy estimation and model selection," in IJCAI'95 - Proceedings of the 14th international joint conference on Artificial intelligence, Vol. 2, (San Francisco, CA: Morgan Kaufmann Publishers), 1137-1145.

Koivunen, E., Tuunainen, P., Rossow, L., and Valaja, J. (2014). Digestibility and utilization of faba bean (Vicia faba L.) diets in broilers. Acta Agric. Scand. Sect. A Anim. Sci. 64, 217-225. doi: 10.1080/09064702.2015.1020857

Kuijken, R. C. P., van Eeuwijk, F. A., Marcelis, L. F. M., and Bouwmeester, H. J. (2015). Root phenotyping: from component trait in the lab to breeding. J. Exp. Bot. 66, 5389-5401. doi: 10.1093/jxb/erv239

Li, L., Zhang, Q., and Huang, D. (2014). A review of imaging techniques for plant phenotyping. Sensors 14, 20078-20111. doi: 10.3390/s141120078

Libbrecht, M. W., and Noble, W. S. (2015). Machine learning applications in genetics and genomics. Nat. Rev. Genet. 16, 321-332. doi: 10.1038/nrg 3920

Liu, N., Koh, Z. X., Goh, J., Lin, Z., Haaland, B., Ting, B. P., et al. (2014). Prediction of adverse cardiac events in emergency department patients with chest pain using machine learning for variable selection. BMC Med. Inform. Decis. Mak. 14:75. doi: 10.1186/1472-6947-14-75

Liu, W., Gopal, S., and Woodcock, C. E. (2004). Uncertainty and confidence in land cover classification using a hybrid classifier approach. Photogramm. Eng. Remote Sensing 70, 963-971. doi: 10.14358/PERS.70.8.963

Lizarazo, C. I., Lampi, A. M., Liu, J., Sontag-Strohm, T., Piironen, V., and Stoddard, F. L. (2015). Nutritive quality and protein production from grain legumes in a boreal climate. J. Sci. Food Agric. 95, 2051-2064. doi: 10.1002/jsfa.6920

Löw, F., Schorcht, G., Michel, U., Dech, S., and Conrad, C. (2012). "Per-field crop classification in irrigated agricultural regions in middle Asia using random forest and support vector machine ensemble," in Proceedings of the SPIE 8538, Earth Resources and Environmental Remote Sensing/GIS Applications III, 85380R, (Edinburgh: International Society for Optics and Photonics), 1-11.
Lynch, J. P. (2007). Roots of the second green revolution. Aust. J. Bot. 55, 493-512. doi: 10.1071/BT06118

Lynch, J. P. (2011). Root phenes for enhanced soil exploration and phosphorus acquisition: tools for future crops. Plant Physiol. 156, 1041-1049. doi: 10.1104/ pp.111.175414

Ma, C., Zhang, H. H., and Wang, X. (2014). Machine learning for Big Data analytics in plants. Trends Plant Sci. 19, 798-808. doi: 10.1016/j.tplants.2014.08.004

Mairhofer, S., Zappala, S., Tracy, S. R., Sturrock, C., Bennett, M., Mooney, S. J., et al. (2012). RooTrak: automated recovery of three-dimensional plant root architecture in soil from $\mathrm{x}$-ray microcomputed tomography images using visual tracking. Plant Physiol. 158, 561-569. doi: 10.1104/pp.111.186221

Manavalan, L. P., Guttikonda, S. K., Nguyen, V. T., Shannon, J. G., and Nguyen, H. T. (2010). Evaluation of diverse soybean germplasm for root growth and architecture. Plant Soil 330, 503-514. doi: 10.1007/s11104-009-0222-8

Meyer, D. (2015). Support Vector Machines. The Interface to Libsvm in Package e1071. Vienna: FH Technikum Wien.

Miguel, M. A. (2012). Functional Role and Synergystic Effect of Root Traits for Phosphorus Acquisition Efficiency and Their Genetic Basis in Common Bean (Phaseolus vulgaris L.). State College, PA: The Pennsylvania State University.

Miguel, M. A., Postma, J. A., and Lynch, J. P. (2015). Phene synergism between root hair length and basal root growth angle for phosphorus acquisition. Plant Physiol. 167, 1430-1439. doi: 10.1104/pp.15.00145

Miguel, M. A., Widrig, A., Vieira, R. F., Brown, K. M., and Lynch, J. P. (2013). Basal root whorl number: a modulator of phosphorus acquisition in common bean (Phaseolus vulgaris). Ann. Bot. 112, 973-982. doi: 10.1093/aob/mct164

Multari, S., Stewart, D., and Russell, W. R. (2015). Potential of Fava bean as future protein supply to partially replace meat intake in the human diet. Compr. Rev. Food Sci. Food Saf. 14, 511-522. doi: 10.1111/1541-4337.12146

Nicodemus, K. K., Callicott, J. H., Higier, R. G., Luna, A., Nixon, D. C., Lipska, B. K., et al. (2010). Evidence of statistical epistasis between DISC1, CIT and NDEL1 impacting risk for schizophrenia: biological validation with functional neuroimaging. Hum. Genet. 127, 441-452. doi: 10.1007/s00439-0090782-y

Okkan, U., and Serbes, Z. A. (2012). Rainfall-runoff modeling using least squares support vector machines. Environmetrics 23, 549-564. doi: 10.1007/s12011010-8678-1

Pan, X.-Y., and Shen, H.-B. (2009). Robust prediction of B-factor profile from sequence using two-stage SVR based on random forest feature selection. Protein pept. lett. 16, 1447-1454. doi: 10.2174/092986609789839250

Pinheiro, H. A., DaMATTA, F. M., Chaves, A. R., Loureiro, M. E., and Ducatti, C. (2005). Drought tolerance is associated with rooting depth and stomatal control of water use in clones of Coffea canephora. Ann. Bot. 96, 101-108. doi: 10.1093/ $\mathrm{aob} / \mathrm{mci} 154$

Poorter, H., Jagodzinski, A. M., Ruiz-Peinado, R., Kuyah, S., Luo, Y., Oleksyn, J., et al. (2015). How does biomass distribution change with size and differ among species? An analysis for 1200 plant species from five continents. New Phytol. 208, 736-749. doi: 10.1111/nph.13571

Preissel, S., Reckling, M., Schläfke, N., and Zander, P. (2015). Magnitude and farmeconomic value of grain legume pre-crop benefits in Europe: a review. Field Crops Res. 175, 64-79. doi: 10.1016/j.fcr.2015.01.012

R Core Team (2015). R: A Language and Environment for Statistical Computing. Vienna: R foundation for Statistical Computing.

Rahaman, M. M., Chen, D., Gillani, Z., Klukas, C., and Chen, M. (2015). Advanced phenotyping and phenotype data analysis for the plant growth and development study. Front. Plant Sci. 6:00619. doi: 10.3389/fpls.2015.00619

Rewald, B., Ephrath, J. E., and Rachmilevitch, S. (2011). A root is a root is a root? Water uptake rates of Citrus root orders. Plant Cell Environ. 34, 33-42. doi: 10.1111/j.1365-3040.2010.02223.x

Rich, S. M., and Watt, M. (2013). Soil conditions and cereal root system architecture: review and considerations for linking Darwin and Weaver. J. Exp. Bot. 64, 1193-1208. doi: 10.1093/jxb/ert043

Sacchet, M. D., Prasad, G., Foland-Ross, L. C., Thompson, P. M., and Gotlib, I. H. (2015). Support vector machine classification of major depressive disorder using diffusion-weighted neuroimaging and graph theory. Front. Psychiatry 6:00021. doi: 10.3389 /fpsyt.2015.00021

Sack, L., and Scoffoni, C. (2013). Leaf venation: structure, function, development, evolution, ecology and applications in the past, present and future. New Phytol. 198, 983-1000. doi: 10.1111/nph.12253 
Shan, C. (2012). Learning local binary patterns for gender classification on realworld face images. Pattern Recognit. Lett. 33, 431-437. doi: 10.1016/j.patrec. 2011.05.016

Shang, X., and Chisholm, L. (2014). Classification of Australian native forest species using hyperspectral remote sensing and machine-learning classification algorithms. JSTARS 7, 2481-2489.

Sommer, C., and Gerlich, D. W. (2013). Machine learning in cell biology-teaching computers to recognize phenotypes. J. Cell Sci. 126, 5529-5539. doi: 10.1242/ jcs. 123604

Stachowicz, J. J., Kamel, S. J., Hughes, A. R., and Grosberg, R. K. (2013). Genetic relatedness influences plant biomass accumulation in eelgrass (Zostera marina). Am. Nat. 181, 715-724. doi: 10.1086/669969

Statnikov, A., Hardin, D., and Aliferis, C. (2006). "Using SVM weight-based methods to identify causally relevant and non-causally relevant variables," in Proceedings of the NIPS 2006 Workshop on Causality and Feature Selection, Whistler, BC.

Steinberga, V., Alsina, I., Ansevica, A., Dubova, L., Liepina, L., and Šterne, D. (2008). The evaluation of effectiveness of Rhizobium lupini strains (In Latvian). Agronomijas Vçstis 10, 193-197.

Strobl, C., Boulesteix, A.-L., Kneib, T., Augustin, T., and Zeileis, A. (2008). Conditional variable importance for random forests. BMC Bioinformatics 9:307. doi: 10.1186/1471-2105-9-307

Strobl, C., Malley, J., and Tutz, G. (2009). An introduction to recursive partitioning: rationale, application, and characteristics of classification and regression trees, bagging, and random forests. Psychol. Methods 14, 323-348. doi: 10.1037/ a0016973

Strobl, C., and Zeileis, A. (2008). Danger: High power!-Exploring the Statistical Properties of a Test for Random Forest Variable Importance. Munich: LudwigMaximilian University of Munich.

Trachsel, S., Kaeppler, S. M., Brown, K. M., and Lynch, J. P. (2011). Shovelomics: high throughput phenotyping of maize (Zea mays L.) root architecture in the field. Plant Soil 341, 75-87. doi: 10.1007/s11104-010-0 623-8

Tracy, S. R., Black, C. R., Roberts, J. A., Sturrock, C., Mairhofer, S., Craigon, J., et al. (2012). Quantifying the impact of soil compaction on root system architecture in tomato (Solanum lycopersicum) by X-ray micro-computed tomography. Ann. Bot. 110, 511-519. doi: 10.1093/aob/mcs031

Tuberosa, R., Salvi, S., Sanguineti, M. C., Landi, P., Maccaferri, M., and Conti, S. (2002). Mapping QTLs regulating morpho-physiological traits and yield: case studies, shortcomings and perspectives in drought-stressed maize. Ann. Bot. 89, 941-963. doi: 10.1093/aob/mcf134

Vadez, V., Rao, S., Kholova, J., Krishnamurthy, L., Kashiwagi, J., Ratnakumar, P., et al. (2008). Root research for drought tolerance in legumes: quo vadis. J. Food Legumes 21, 77-85.
Vapnik, V. N., and Vapnik, V. (1998). Statistical Learning Theory, Vol. 1. New York, NY: Wiley.

Vaz Patto, M. C., Amarowicz, R., Aryee, A. N. A., Boye, J. I., Chung, H.-J., MartínCabrejas, M. A., et al. (2014). Achievements and challenges in improving the nutritional quality of food legumes. Crit. Rev. Plant Sci. 34, 105-143. doi: $10.1080 / 07352689.2014 .897907$

Verikas, A., Gelzinis, A., and Bacauskiene, M. (2011). Mining data with random forests: a survey and results of new tests. Pattern Recognit. 44, 330-349. doi: 10.1016/j.patcog.2010.08.011

Wang, L., Huang, C., and Yang, J. Y. (2010). Predicting siRNA potency with random forests and support vector machines. BMC Genomics 11:S2. doi: 10. 1186/1471-2164-11-S3-S2

Watt, M., Moosavi, S., Cunningham, S. C., Kirkegaard, J. A., Rebetzke, G. J., and Richards, R. A. (2013). A rapid, controlled-environment seedling root screen for wheat correlates well with rooting depths at vegetative, but not reproductive, stages at two field sites. Ann. Bot. 112, 447-455. doi: 10.1093/aob/mct122

Wojciechowski, T., Gooding, M. J., Ramsay, L., and Gregory, P. J. (2009). The effects of dwarfing genes on seedling root growth of wheat. J. Exp. Bot. 60, 2565-2573. doi: 10.1093/jxb/erp107

Yang, J., Yao, D., Zhan, X., and Zhan, X. (2014). "Predicting disease risks using feature selection based on random forest and support vector machine," in Bioinformatics Research and Applications, Vol. 8492, eds M. Basu, Y. Pan, and J. Wang (Berlin: Springer), 1-11.

Zheng, B., Yoon, S. W., and Lam, S. S. (2014). Breast cancer diagnosis based on feature extraction using a hybrid of K-means and support vector machine algorithms. Expert Syst. Appl. 41, 1476-1482. doi: 10.1016/j.eswa.2013.08.044

Zhong, D., Novais, J., Grift, T. E., Bohn, M., and Han, J. (2009). Maize root complexity analysis using a support vector machine method. Comput. Electron. Agric. 69, 46-50. doi: 10.1016/j.compag.2009.06.013

Zhu, Z., Woodcock, C. E., Rogan, J., and Kellndorfer, J. (2012). Assessment of spectral, polarimetric, temporal, and spatial dimensions for urban and periurban land cover classification using Landsat and SAR data. Remote Sensing Environ. 117, 72-82. doi: 10.1016/j.rse.2011.07.020

Conflict of Interest Statement: The authors declare that the research was conducted in the absence of any commercial or financial relationships that could be construed as a potential conflict of interest.

Copyright (c) 2016 Zhao, Bodner and Rewald. This is an open-access article distributed under the terms of the Creative Commons Attribution License (CC BY). The use, distribution or reproduction in other forums is permitted, provided the original author(s) or licensor are credited and that the original publication in this journal is cited, in accordance with accepted academic practice. No use, distribution or reproduction is permitted which does not comply with these terms. 